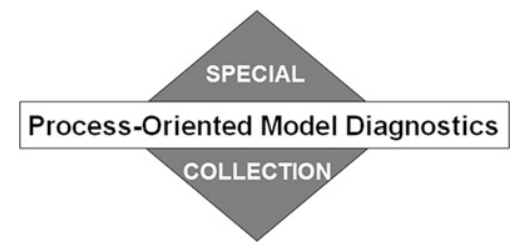

\title{
MJO Teleconnections over the PNA Region in Climate Models. Part II: Impacts of the MJO and Basic State
}

\author{
JIABAO WANG AND HYEMI KIM \\ School of Marine and Atmospheric Sciences, Stony Brook University, State University of New York, Stony Brook, New York \\ DAEHYUN KIM \\ Department of Atmospheric Sciences, University of Washington, Seattle, Washington \\ STEPHANIE A. HENDERSON \\ Department of Atmospheric and Oceanic Sciences, University of Wisconsin-Madison, Madison, Wisconsin \\ CRISTIANA STAN \\ Department of Atmospheric, Oceanic, and Earth Sciences, George Mason University, Fairfax, Virginia \\ ERIC D. MALONEY \\ Department of Atmospheric Science, Colorado State University, Fort Collins, Colorado
}

(Manuscript received 22 November 2019, in final form 16 March 2020)

\begin{abstract}
In an assessment of 29 global climate models (GCMs), Part I of this study identified biases in boreal winter MJO teleconnections in anomalous 500-hPa geopotential height over the Pacific-North America (PNA) region that are common to many models: an eastward shift, a longer persistence, and a larger amplitude. In Part II, we explore the relationships of the teleconnection metrics developed in Part I with several existing and newly developed MJO and basic state (the mean subtropical westerly jet) metrics. The MJO and basic state diagnostics indicate that the MJO is generally weaker and less coherent and propagates faster in models compared to observations. The mean subtropical jet also exhibits notable biases such as too strong amplitude, excessive eastward extension, or southward shift. The following relationships are found to be robust among the models: 1) models with a faster MJO propagation tend to produce weaker teleconnections; 2) models with a less coherent eastward MJO propagation tend to simulate more persistent MJO teleconnections; 3 ) models with a stronger westerly jet produce stronger and eastward shifted MJO teleconnections; 4) models with an eastward extended jet produce an eastward shift in MJO teleconnections; and 5) models with a southward shifted jet produce stronger MJO teleconnections. The results are supported by linear baroclinic model experiments. Our results suggest that the larger amplitude and eastward shift biases in GCM MJO teleconnections can be attributed to the biases in the westerly jet, and that the longer persistence bias is likely due to the lack of coherent eastward MJO propagation.
\end{abstract}

\section{Introduction}

The Madden-Julian oscillation (MJO; Madden and Julian 1971, 1972) is characterized by the eastward propagation of a planetary-scale convectively coupled system in the equatorial Indo-Pacific warm pool with an average phase speed of about $5 \mathrm{~m} \mathrm{~s}^{-1}$. It takes approximately 30 to

Corresponding author: Hyemi Kim, hyemi.kim@stonybrook.edu
60 days for an MJO event to travel from the western Indian Ocean to the date line, around where the convective signal tends to cease. Diabatic heating related to the MJO leads to the formation of an anomalous Rossby wave source (RWS) in the subtropics and midlatitudes through anomalous upper-level divergent winds in regions with a strong absolute vorticity gradient near the subtropical westerly jet (e.g., Sardeshmukh and Hoskins 1988). Excited Rossby waves propagate poleward and eastward into the 
extratropics and modulate circulations there (e.g., Horel and Wallace 1981; Hoskins and Karoly 1981). MJO teleconnections can significantly modulate midlatitude weather and climate phenomena such as blocking events (Henderson et al. 2016), precipitation and temperature (Zhou et al. 2012; Zheng et al. 2018), atmospheric rivers (Mundhenk et al. 2016), storm tracks (Deng and Jiang 2011; Wang et al. 2018a; Zheng et al. 2018), the North Atlantic Oscillation (Cassou 2008; Lin et al. 2009), and the Pacific-North American (PNA) pattern (Mori and Watanabe 2008; Tseng et al. 2019; Henderson et al. 2020, manuscript submitted to J. Climate). Given the broad impacts of MJO teleconnections, a better understanding of the factors that influence MJO teleconnections and their accurate simulation in global climate models (GCMs) is crucial to both the research and operational communities. The Working Group on Numerical Experimentation (WGNE) MJO Task Force adopted this as one of the priority subprojects as a joint activity with the World Meteorological Organization (WMO) Subseasonalto-Seasonal (S2S) teleconnection subproject. The scientific focuses of the joint activity include 1) development of standardized MJO teleconnection diagnostics (Wang et al. 2019, hereafter Part I) and 2) analysis of the sensitivity of MJO teleconnections to MJO and basic state representations in models and sources of teleconnection biases (the focus of the present paper).

It is reasonable to expect $\mathrm{MJO}$ teleconnections over the PNA region in a model to be affected by the model's own MJO characteristics such as its amplitude, propagation speed, and extent. The amplitude of MJO teleconnections would be stronger when the MJO and associated RWS is stronger (Wang et al. 2018a). MJO teleconnections would also intensify if the MJO propagates farther eastward into the central Pacific rather than weakens or breaks down over the Maritime Continent (the "Maritime Continent barrier effect"; Rui and Wang 1990; Kim et al. 2014a). This is because extraction of kinetic energy from the mean flow by the Rossby wave is known to be particularly efficient in the jet exit region (Adames and Wallace 2014; Bao and Hartmann 2014). On the other hand, MJO teleconnections would be weaker if the MJO propagates with a phase speed that is faster than the average (Bladé and Hartmann 1995; Yadav and Straus 2017; Goss and Feldstein 2018; Zheng and Chang 2019). According to Bladé and Hartmann (1995), this is because 1) a faster propagating $\mathrm{MJO}$ is equivalent to embedding the forcing in strong relative easterly winds, which gives rise to an enhanced equatorial trapping of Rossby waves, and 2) the faster propagating MJO leads to a decrease in the Rossby wave group velocity, which causes a greater wave damping during its propagation. The weaker teleconnection amplitude may also arise from the weaker teleconnection persistence as the MJO heating and associated RWS would transit more rapidly from one phase to the next phase for a fast propagating MJO (Zheng and Chang 2019).

MJO teleconnections are also influenced by the basic state in the extratropics. In boreal winter, anomalous vorticity generation reaches a maximum at the southern boundary of the subtropical westerly jet where the absolute vorticity gradient is at maximum (Sardeshmukh and Hoskins 1988). The excited Rossby waves are refracted toward regions of high stationary wavenumber $K_{S}$. Thus the westerly jet, where $K_{S}$ is maximized, acts as a waveguide (Hoskins and Ambrizzi 1993). On the poleward and equatorward sides of the jet, the meridional gradient of absolute vorticity $\left(\beta^{*}=\partial f / \partial y-\partial^{2} \bar{u} / \partial y^{2}\right)$ is small or can become negative due to strong meridional curvature $\left(\partial^{2} \bar{u} / \partial y^{2}\right)$. This is the region where Rossby waves are reflected, and they must propagate eastward along the jet and emanate at the exit region (Karoly 1983; Simmons et al. 1983; Hoskins and Ambrizzi 1993; Seo and Lee 2017).

The above considerations strongly suggest that simulation of MJO teleconnections in GCMs can be improved with a more realistic MJO (Yoo et al. 2015; Stan and Straus 2019) or the basic state in the extratropics, in particular the amplitude and position of the westerly jet. While it has been documented that many current GCMs still produce a weaker MJO with faster and less coherent eastward propagation (e.g., Kim et al. 2014b; Ahn et al. 2017) than the observed and a stronger Pacific westerly jet with an eastward extension (Gong et al. 2014; Henderson et al. 2017), a systematic examination of the relationship between MJO teleconnections and the characteristics of the $\mathrm{MJO}$ and the subtropical jet using a large set of GCM simulations has not been performed.

In Part I, a set of standardized MJO teleconnection metrics was developed for objectively evaluating and comparing boreal winter MJO teleconnections (defined using the $500-\mathrm{hPa}$ geopotential height anomalies, $\mathrm{Z} 500 \mathrm{a})$ over the PNA region $\left(20^{\circ}-80^{\circ} \mathrm{N}, 120^{\circ} \mathrm{E}-60^{\circ} \mathrm{W}\right)$ in the $29 \mathrm{GCMs}$ relative to reanalysis fields. It is shown that current GCMs generally produce MJO teleconnections with an eastward shift, larger amplitude, and longer persistence compared to those observed. Here in Part II we investigate how these MJO teleconnection biases relate to MJO and basic state characteristics. The hypotheses arising from this initial investigation are further tested with a linear baroclinic model (LBM; Watanabe and Kimoto 2000).

The paper is organized as follows. The GCMs and reference data are introduced in section 2. Five MJO skill metrics and their relationships with MJO teleconnections are discussed in section 3. Four basic state metrics and 
TABLE 1. Description of CMIP5 (1-22), GASS/YoTC (23-28), and ECMWF (29) models. Models in bold are 12 "good" MJO propagation models selected based on MJO propagation skill (M1).

\begin{tabular}{|c|c|c|c|}
\hline & Model & Modeling center & Institution \\
\hline 1 & ACCESS1.0 & CSIRO-BOM & $\begin{array}{l}\text { CSIRO (Commonwealth Scientific and Industrial Research } \\
\text { Organization), and BOM (Bureau of Meteorology), Australia }\end{array}$ \\
\hline 2 & ACCESS1.3 & & \\
\hline 3 & CanESM2 & CCCma & Canadian Centre for Climate Modeling and Analysis, Canada \\
\hline 4 & CMCC-CESM & $\mathrm{CMCC}$ & Centro Euro-Mediterraneo per I Cambiamenti Climatici, Italy \\
\hline 5 & CMCC-CM & & \\
\hline 6 & CMCC-CMS & & \\
\hline 7 & CNRM-CM5 & CNRM-CERFACS & $\begin{array}{l}\text { Centre National de Recherches Meteorologiques/Centre Europeen de } \\
\text { Recherche et Formation Avancees en Calcul Scientifique, France }\end{array}$ \\
\hline 8 & GFDL CM3 & NOAA GFDL & Geophysical Fluid Dynamics Laboratory, United States \\
\hline 9 & GFDL-ESM2G & & \\
\hline 10 & GFDL-ESM2M & & \\
\hline 11 & HadGEM2-AO & MOHC & Met Office Hadley Centre, United Kingdom \\
\hline 12 & HadGEM2-CC & & \\
\hline 13 & IPSL-CM5A-LR & IPSL & Institut Pierre-Simon Laplace, France \\
\hline 14 & MIROC5 & MIROC & Atmosphere and Ocean Research Institute (The University of Tokyo), \\
\hline 15 & MIROC-ESM & & National Institute for Environmental Studies, and Japan Agency for \\
\hline 16 & MIROC-ESM-CHEM & & Marine-Earth Science and Technology, Japan \\
\hline 17 & MPI-ESM-LR & MPI-M & Max Planck Institute for Meteorology, Germany \\
\hline 18 & MPI-ESM-MR & & \\
\hline 19 & MPI-ESM-P & & \\
\hline 20 & MRI-CGCM3 & MRI & Meteorological Research Institute, Japan \\
\hline 21 & MRI-ESM1 & & \\
\hline 22 & NorESM1-M & $\mathrm{NCC}$ & Norwegian Climate Centre \\
\hline 23 & GISS-E2 & NASA GISS & NASA Goddard Institute for Space Studies \\
\hline 24 & MRI-AGCM3 & MRI & Meteorological Research Institute, Japan \\
\hline 25 & SPCAM3 & & Colorado State University \\
\hline 26 & SPCCSM3 & & George Mason University \\
\hline 27 & TAMU-CAM4 & & Texas A\&M University \\
\hline 28 & NCAR-CAM5 & NCAR & National Center for Atmospheric Research \\
\hline 29 & ECMWF & ECMWF & European Centre for Medium-Range Weather Forecasts \\
\hline
\end{tabular}

their relationships with MJO teleconnections are discussed in section 4. A description of the LBM and the results of sensitivity experiments are provided in section 5 , followed by a summary and discussion in section 6 .

\section{GCMs and reference dataset}

Since we use the same models and reference dataset as in Part I, they are only briefly described here. A total of 29 GCMs are analyzed (Table 1): 22 CMIP5 models (Taylor et al. 2012), 6 models from the Global Energy and Water Cycle Experiment (GEWEX) Atmospheric System Study and Year of Tropical Convection (GASS/ YoTC) project (Jiang et al. 2015), and one Atmospheric Model Intercomparison Project (AMIP) run from the European Centre for Medium-Range Weather Forecasts (ECMWF) (Davini et al. 2017). The period analyzed in this study is 1975-2005 for CMIP5 models, 1991-2010 for GASS/YoTC models (except for SPCAM, for which 1986-2003 is used), and 1980-2000 for the ECMWF model. Only one ensemble member from each model is analyzed.
The NOAA Advanced Very High Resolution Radiometer OLR (Liebmann and Smith 1996) dataset and ERA-Interim data (Dee et al. 2011) from 1979 to 2017 are analyzed (hereafter referred to as "observations"). We focus on October to March when the MJO and Northern Hemisphere teleconnections are most prominent. Model output and reference data are interpolated to the same horizontal resolution $\left(2.5^{\circ} \times 2.5^{\circ}\right)$. Anomalies are derived by subtracting the first three harmonics of the climatological seasonal cycle and the most recent 120-day mean from each field to reduce the influence of interannual variability (Wheeler and Hendon 2004). No filtering is applied unless stated otherwise.

\section{MJO simulation and its influence on MJO teleconnections}

\section{a. MJO simulation (MJO skill metrics M1-M5)}

Several MJO metrics developed by previous studies (e.g., Kim et al. 2009; Waliser et al. 2009; Jiang et al. 2015; Ahn et al. 2017) are applied to the 29 GCMs. Figure 1 shows Hovmöller diagrams (longitude vs time 

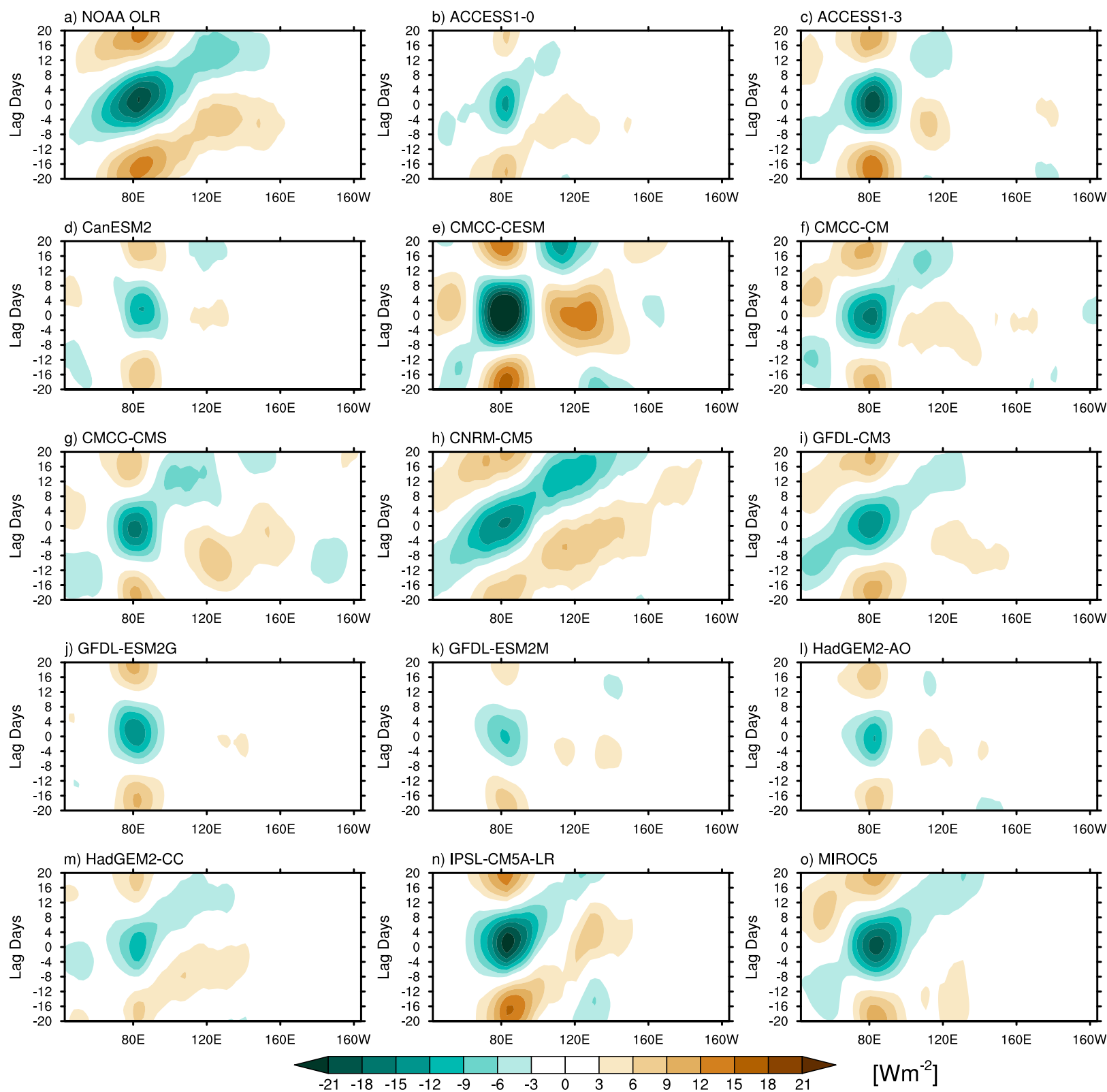

FIG. 1. Lead-lag composites of $10^{\circ} \mathrm{S}-10^{\circ} \mathrm{N}$ averaged (a) observed and (b)-(dd) modeled 25-90-day filtered OLR anomalies (unit: W m ${ }^{-2}$ ) against convection averaged over the eastern Indian Ocean $\left(5^{\circ} \mathrm{S}-5^{\circ} \mathrm{N}, 75^{\circ}-85^{\circ} \mathrm{E}\right)$ with standard deviation less than -1 .

lag) of $10^{\circ} \mathrm{S}-10^{\circ} \mathrm{N}$ averaged $25-90$-day filtered OLR anomalies using a Lanczos filter (Duchon 1979). Day 0 corresponds to the day when the standard deviation of OLR anomaly averaged over the eastern Indian Ocean $\left(5^{\circ} \mathrm{S}-5^{\circ} \mathrm{N}, 75^{\circ}-85^{\circ} \mathrm{E}\right)$ is less than -1 , day 1 is the lag composite of OLR anomaly one day after day 0 , and so on. A majority of models do not simulate realistic eastward MJO propagation. Some models (e.g., GFDLESM2G, GFDL-ESM2M, HadGEM2-AO, MIROCESM, MIROC-ESM-CHEM, and NCAR CAM5) produce a stationary MJO. CanESM2 shows westward propagation. To quantify how well a model simulates eastward MJO propagation, a metric M1 is developed following Jiang et al. (2015).

(M1) MJO propagation skill: The pattern correlation coefficient (pattern CC) is calculated between the observed and model's Hovmöller diagram of OLR anomalies: one for the composites against convection averaged over the eastern Indian Ocean (Fig. 1) and another against the corresponding western Pacific $\left(130^{\circ}-150^{\circ} \mathrm{E}\right.$, $5^{\circ} \mathrm{S}-5^{\circ} \mathrm{N}$ ) time series [not shown; more details in Jiang et al. (2015)]. Metric M1 is derived as the average of these 

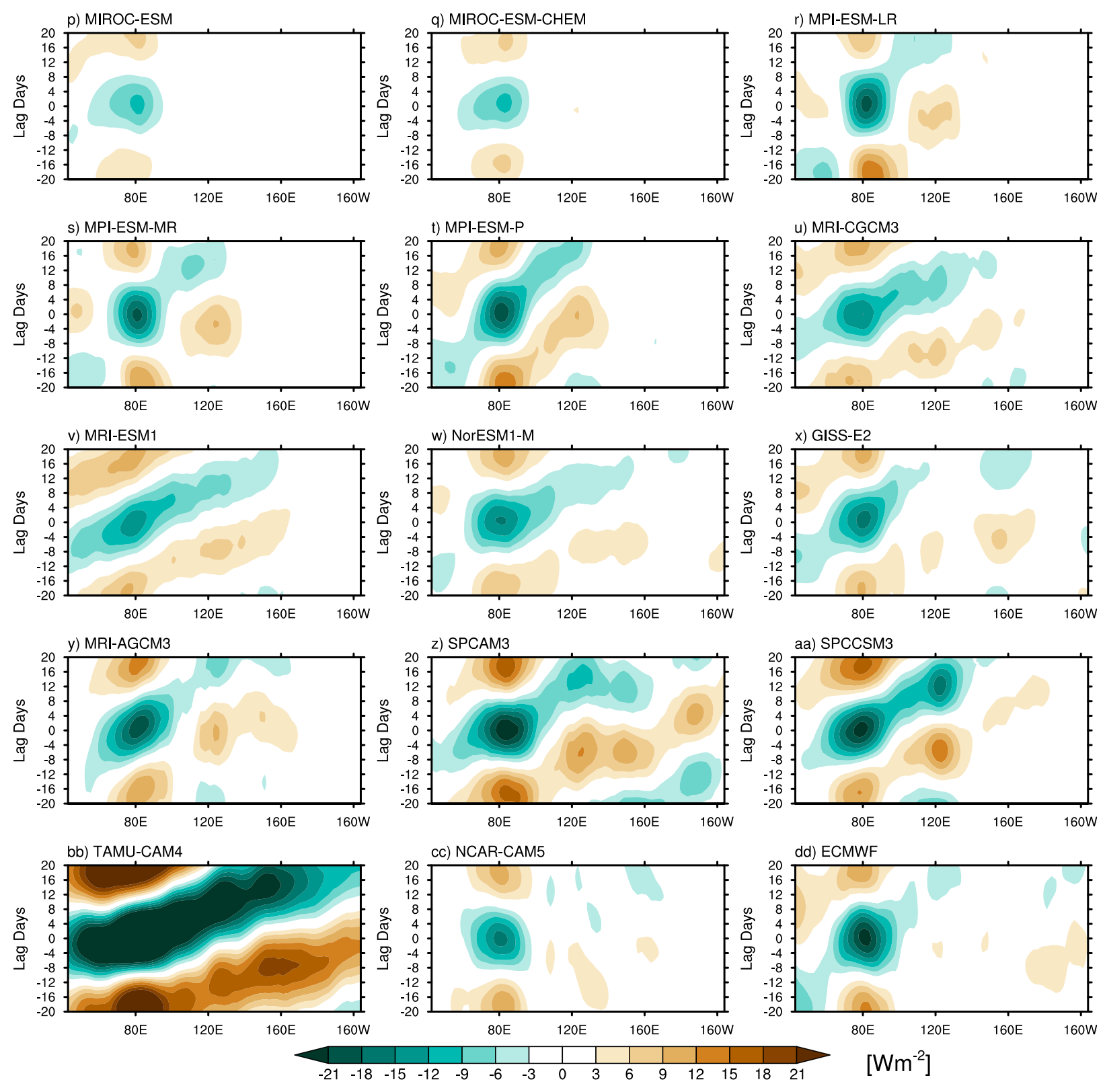

FIG. 1. (Continued)

two pattern CCs and ranges from 0.5 to 0.9 among models (Fig. 2a). "Good" MJO models are defined when M1 exceeds 0.75 (a total of 12 models, bolded in Table 1). These models are consistent with the "good" MJO models analyzed in Jiang et al. (2015) and Henderson et al. (2017), who used lag regression and lag correlation, respectively, to construct the Hovmöller diagrams for selecting the "good" MJO models.

(M2) Coherency: this metric aims to characterize the coherency of the eastward MJO propagation. Following Sperber and Kim (2012) and Ahn et al. (2017), M2 is the average of the absolute values of maximum and minimum lead-lag correlation coefficients calculated between the Real-time Multivariate MJO (RMM; Wheeler and Hendon 2004) indices. As in Part I, the model RMM indices are constructed by projecting the $15^{\circ} \mathrm{S}-15^{\circ} \mathrm{N}$ averaged OLR and $850-$ and $200-\mathrm{hPa}$ zonal wind anomalies onto the observed combined EOF (CEOF) eigenvectors (hereafter referred to as "projected RMM indices"). This projection technique (Duffy et al. 2003) allows a direct and consistent comparison of the MJO among models and observations. M2 calculated using the projected RMM indices (Fig. 2b) is highly correlated (correlation coefficient at 0.91 ) with that using RMM 
a) M1 MJO propagation skill

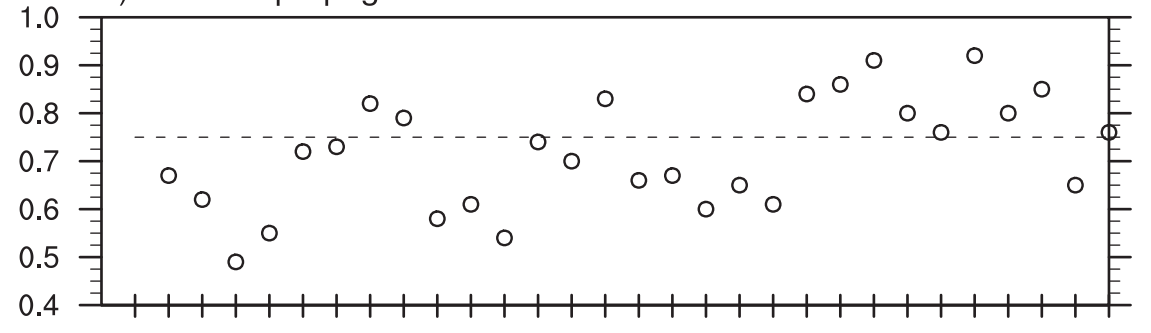

b) M2 Coherency

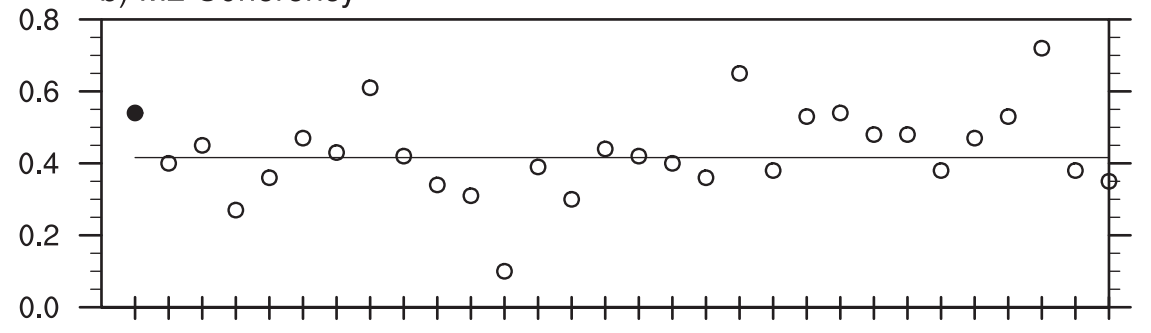

c) M3 Period (days)

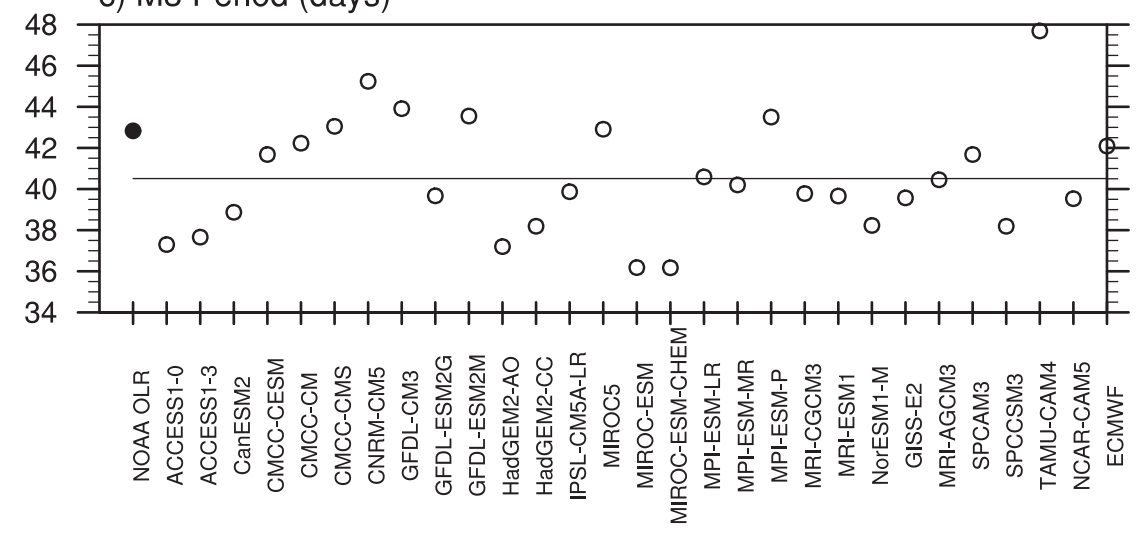

FIG. 2. (a) MJO propagation skill (M1), (b) coherency (M2), and (c) period (M3) for observations (closed circles) and each model (open circles). Solid lines represent the multimodel mean. Dashed line in (a) denotes the threshold (correlation at 0.75) of "good" MJO propagation models.

indices derived from each model's eigenvectors. A smaller M2 value indicates a weaker relationship between the two RMM indices, and thus less coherent eastward propagation of MJO convection from the Indian Ocean to the western Pacific. Most models $(\sim 89 \%)$ have M2 values that are lower than that from observations (0.54), which is consistent with the findings of Ahn et al. (2017).

Metric M3 is calculated based on the wavenumberfrequency power spectrum of $10^{\circ} \mathrm{S}-10^{\circ} \mathrm{N}$ averaged OLR following Ahn et al. (2017). Power spectra for observations, the six GASS/YoTC models, and the ECMWF model are compared in Fig. 3. Corresponding CMIP5 model results can be found in Fig. 1 of Ahn et al. (2017) for precipitation and $850-\mathrm{hPa}$ zonal wind. In observations (Fig. 3a), the power peaks within the 30-80-day period at wavenumbers 1-3 (usually referred to as the
"MJO band"), which is consistent with previous studies (e.g., Zhang et al. 2006; Kim et al. 2009; Ahn et al. 2017). The models have large biases in the spatial and temporal scale of the MJO. Eastward power in GISS-E2, MRIAGCM3, SPCCSM3, and ECMWF peaks at a much lower frequency/longer period $(\sim 100$-day period) at zonal wavenumbers 1-3. ECMWF, TAMU, and SPCAM3 strongly overestimate the eastward power within the MJO band, while GISS-E2 and NCAR-CAM5 underestimate it. A metric M3 is developed to quantify the MJO period in model simulations:

(M3) MJO period: The average period is calculated as the sum of the power-weighted period divided by the sum of power over the 25-100-day period for zonal wavenumbers 1-3 (red box in Fig. 3a). This broad period range is selected given the large model spread in the 
a) NOAA OLR

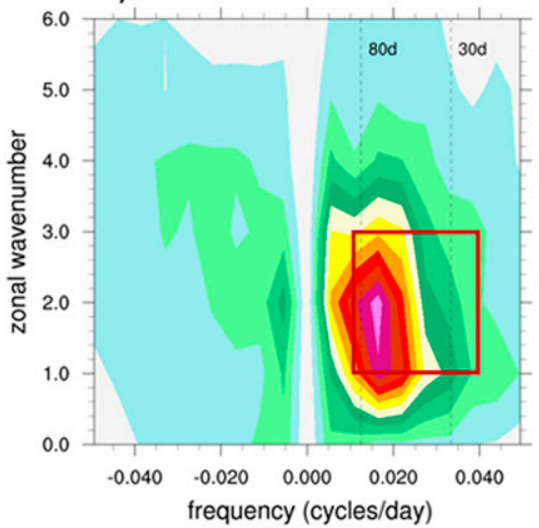

d) SPCAM3

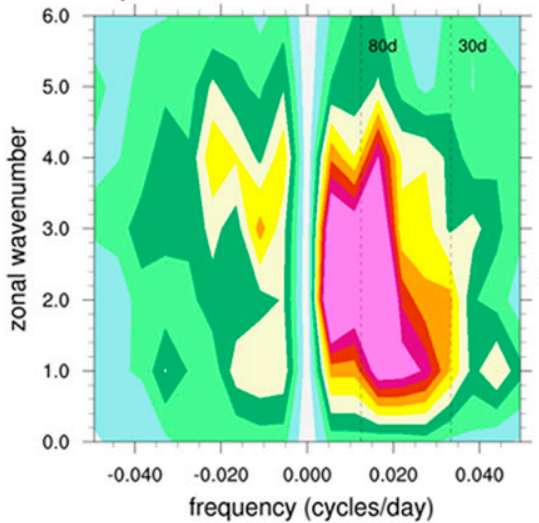

g) NCAR-CAM5

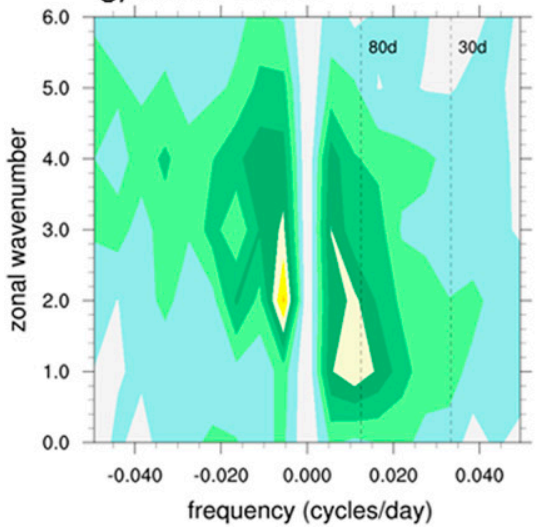

b) GISS-E2

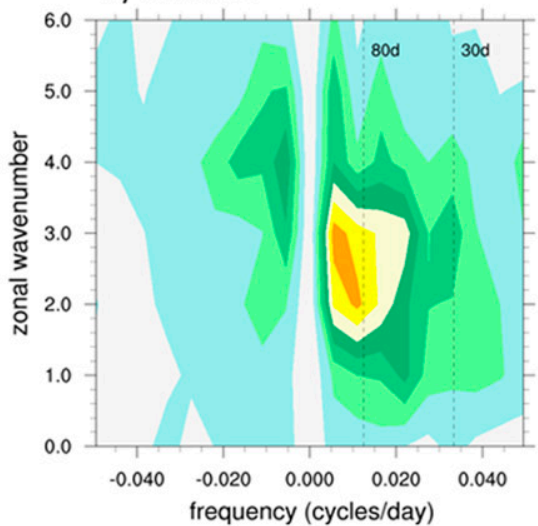

e) SPCCSM3

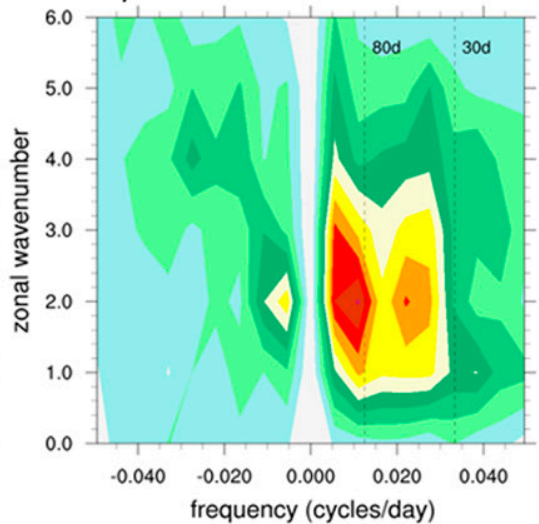

h) ECMWF

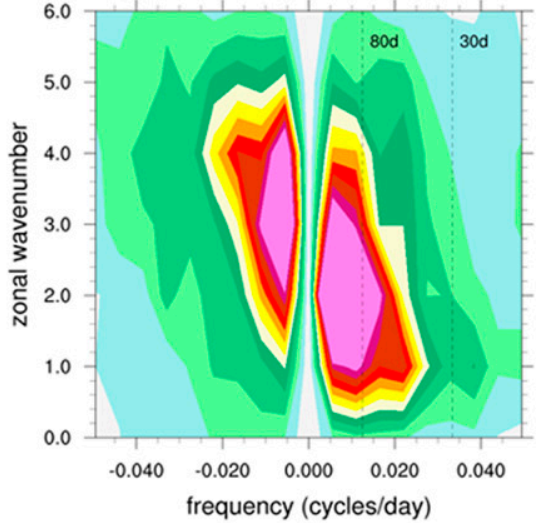

c) MRI-AGCM3

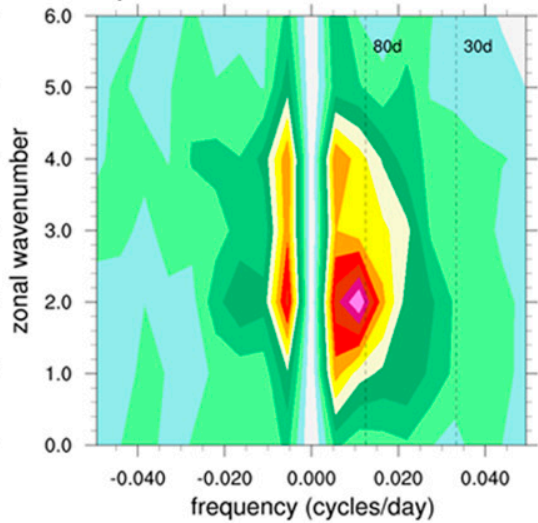

f) TAMU-CAM4
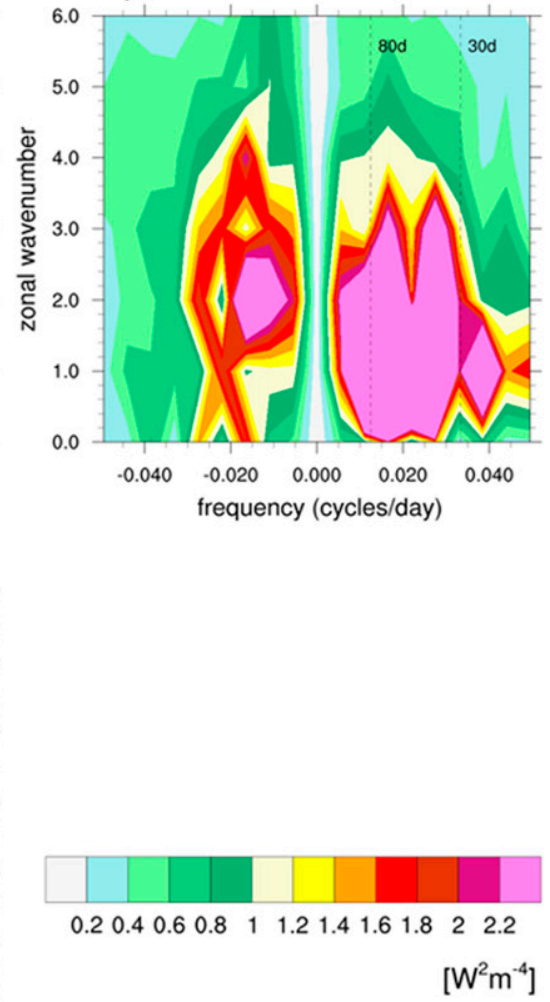

FIG. 3. Wavenumber-frequency power spectra of $10^{\circ} \mathrm{S}-10^{\circ} \mathrm{N}$ averaged OLR (unit: $\mathrm{W}^{2} \mathrm{~m}^{-4}$ per frequency interval per wavenumber interval) for (a) observations and (b)-(h) models. Power spectrum is calculated for each year and then averaged over all years. Dotted lines are drawn at frequencies corresponding to 30 and 80 days. The red box in (a) is the band where period (M3) is calculated.

dominant MJO period. The observed MJO period is approximately 43 days. About $75 \%$ of models have a shorter MJO period than observations (Fig. 2c), indicating faster MJO propagation than the observed average phase speed in most GCMs consistent with Ahn et al. (2017). Simulated MJO period is especially short in MIROC-ESM and MIROC-ESM-CHEM at around
36 days, and longer in TAMU-CAM4 at around 48 days. The MJO period estimated from the lead-lag correlation between the projected RMM indices (Ahn et al. 2017) are highly correlated with M3 across all models (correlation coefficient at 0.74).

Metrics M4 and M5 are developed from the composites of OLR anomalies of strong MJO events defined 


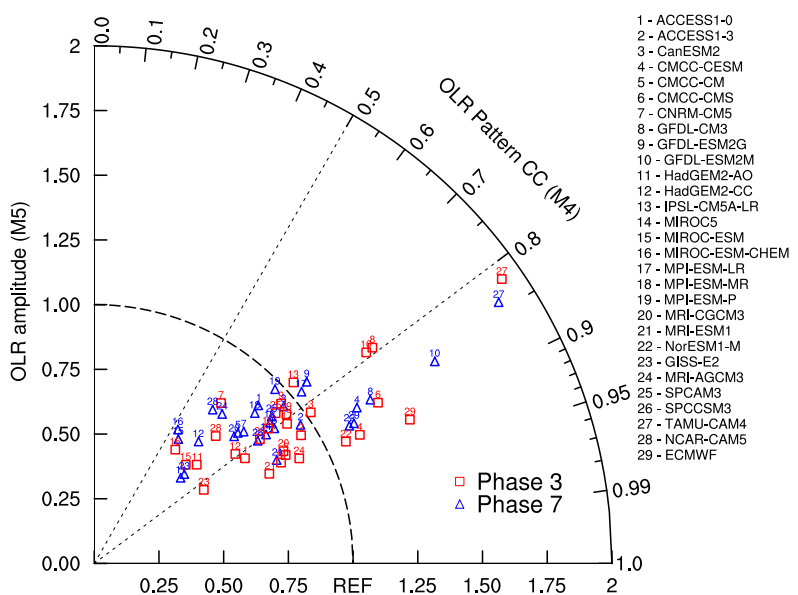

FIG. 4. Taylor diagram of OLR pattern CC (M4) and OLR amplitude (M5) for MJO phase 3 (red square) and phase 7 (blue triangle). The distance between each model and the reference point "REF" indicates the root-mean-square error (RMSE).

when the amplitude of the projected RMM indices exceeds 1.0 .

(M4) OLR pattern CC: Pattern CC is calculated between the modeled and observed OLR anomalies (Fig. 1 of Part I) over the tropical Indo-Pacific region $\left(40^{\circ} \mathrm{E}-\right.$ $\left.140^{\circ} \mathrm{W}, 15^{\circ} \mathrm{S}-15^{\circ} \mathrm{N}\right)$. Results for MJO phases 3 and 7 are summarized in Fig. 4. These phases are the most effective MJO phases in exciting extratropical circulation anomalies (Stan et al. 2017; Tseng et al. 2019). All models reasonably simulate the MJO OLR pattern (M4 > 0.5). In particular, ACCESS1.3, CMCC-CESM, MIROC5, MRI-ESM1, NorESM1-M, TAMU-CAM4, and ECMWF simulate a rather realistic MJO pattern for both phases 3 and 7 (M4 > 0.8). Among the eight MJO phases, models simulate a more realistic MJO OLR pattern for phases 2, 3, and 6 (multimodel mean of M4 greater than 0.75 ).

(M5) OLR amplitude: OLR amplitude is calculated as the standard deviation of composite OLR anomalies over the Indo-Pacific region in a model divided by that of observations (Taylor 2001). A value less than 1 indicates an underestimate of the OLR amplitude in a model. Most models $(\sim 70 \%)$ underestimate the amplitude of MJO convection for both phases 3 and 7 (Fig. 4) compared to observations. This overall weaker MJO is found in all MJO phases (not shown). TAMU-CAM4 has an exceptionally strong MJO amplitude because the model heating is constrained by the observed MJO heating structure. This improves some aspects of MJO characteristics, such as a more realistic eastward propagation (Lappen and Schumacher 2012), but produces too strong amplitude (Jiang et al. 2015).

\section{b. Relationships between the MJO and MJO teleconnections}

Most of the models produce a weaker MJO with faster and less coherent eastward propagation, consistent with previous studies (e.g., Ahn et al. 2017). Impacts of these MJO biases on MJO teleconnections are now examined. MJO teleconnection metrics (T1-T6) are defined by 5-9-day averaged lagged response of Z500a over the PNA region to each MJO phase (more details in Part I). Pattern CC of MJO teleconnections (T1) and of RWS (T6) represents the general simulation skill of the teleconnection pattern. Relative amplitude (T2) is defined similar to OLR amplitude (M5) such that T2 $>1.0$ indicates stronger MJO teleconnections in a model than observations. East-west position (T3) is defined as the Z500a-weighted average longitude, which indicates the east-west shift of MJO teleconnections relative to observations; more positive value of $\mathrm{T} 3$ represents a more eastward shift. Intraphase pattern consistency (IPC) (T4) measures the consistency of teleconnection patterns between individual $\mathrm{MJO}$ events for a given MJO phase; larger IPC indicates a higher consistency. Persistence (T5) represents the duration that teleconnections persist. Table 2 shows the linear correlation coefficients calculated between the MJO and teleconnection metrics across all models. Only metrics with statistically significant correlation coefficients are listed. For correlations with teleconnection amplitude (T2), the outlier model HadGEM2-AO is removed from the

TABLE 2. Correlations between MJO teleconnection and MJO metrics calculated across all models that exceed $90 \%$ confidence level based on a two-tailed test: (T1) pattern CC, (T2) relative amplitude, (T4) intraphase pattern consistency (IPC), (T6) pattern CC of RWS, (T5) persistence; (M1) MJO propagation skill, (M2) coherency, (M3) period, (M4) OLR pattern CC, and (M5) OLR amplitude. Correlations are the average over all phases except T5, which is the average of phases 3 and 7 . Correlations in bold text denote the results after removing the outlier model HadGEM2-AO from calculation (results for all models are shown in parentheses).

\begin{tabular}{|c|c|c|c|c|c|}
\hline & T1 (pattern) & T2 (amplitude) & T4 (IPC) & T6 (RWS pattern) & $\mathrm{T} 5_{\mathrm{p} 3 \& 7}$ (persistence) \\
\hline M1 (propagation) & 0.36 & & & 0.34 & -0.35 \\
\hline M2 (coherency) & 0.56 & & & 0.42 & -0.56 \\
\hline M3 (period) & & $\mathbf{0 . 5 3}(0.23)$ & & & \\
\hline M4 (pattern) & 0.58 & & & 0.61 & \\
\hline M5 (amplitude) & & $\mathbf{0 . 6 1}(0.25)$ & 0.45 & & 0.37 \\
\hline
\end{tabular}


calculation due to an exceptionally large bias in the teleconnection amplitude (Part I).

Table 2 suggests that the model MJO affects the pattern of MJO teleconnections via affecting the RWS pattern. Models with a better and more coherent eastward MJO propagation (M1 and M2 are correlated at 0.77 ) and realistic MJO pattern (M4) generally simulate more realistic patterns of teleconnections (T1) and the RWS (T6). Models with a slower MJO propagation (M3) tend to produce stronger MJO teleconnections (T2) (this will be tested in section 5; Bladé and Hartmann 1995; Yadav and Straus 2017; Goss and Feldstein 2018; Zheng and Chang 2019). Models with stronger MJO amplitude (M5) produce stronger MJO teleconnections (T2) with more consistent teleconnection patterns between individual MJO events (T4) and longer persistence (T5). This influence is possibly because stronger MJO convection can intensify the extratropical response (Wang et al. 2018a), which may lead to a slower decay and longer persistence of teleconnections. This, in turn, gives rise to a higher consistency of teleconnection patterns between individual $\mathrm{MJO}$ events.

Models with a better and more coherent MJO propagation (M1 and M2) have more realistic teleconnection persistence (T5) for phases 3 and 7. The averaged persistence of phases 3 and 7 for "good" MJO propagation models is 15 days, which is closer to the observed (13 days) compared to the rest of models ( $\sim 20$ days). The more realistic teleconnection persistence is possibly because MJO teleconnection changes correspond to a clear MJO transition from one phase to another. This hypothesis is tested with an LBM experiment in section 5 . As a side note, although both MJO propagation (M1 and M2) and MJO amplitude (M5) are associated with teleconnection persistence (T5), no significant correlation is found between the MJO propagation and amplitude.

\section{Basic state simulation and its influence on MJO teleconnections}

\section{a. Basic state simulation (basic state skill metrics B1-B4)}

Generation and propagation of Rossby waves are strongly dependent on the position and intensity of the subtropical westerly jet. Simulation of upper-level zonal wind and its influence on MJO teleconnections is investigated in this section. Figure 5 shows the climatology of 250-hPa zonal wind (U250) in observations and biases in models. Significant biases in both the amplitude and position of the subtropical jet are found. For example, IPSL-CM5A-LR, MRI-CGCM3, and MRI-ESM1 simulate a stronger jet with significant eastward extension, while MIROC-ESM and MIROC-ESM-CHEM produce a westward retracted jet. Four basic state metrics (B1-B4) are developed based on Fig. 5.

(B1) RMSE: Root-mean-square error (RMSE) quantifies the basic state bias due to biases in the amplitude and position of the jet. Following Henderson et al. (2017), we first identify the latitude of the maximum U250 for each model and observations, extend the latitudes $10^{\circ}$ to both the north and south of this maximum latitude, and then calculate the RMSE between the model and observations over these latitudes across the longitude span of $100^{\circ} \mathrm{E}-120^{\circ} \mathrm{W}$. RMSE is extremely large for IPSL-CM5A-LR, MRI-CGCM3, and MRI-ESM1, and small for SPCCSM3 and NCAR-CAM5 (Fig. 6a). The amplitude and position bias are further separated into metrics B2-B4.

(B2) Jet amplitude: To estimate the biases induced from the jet amplitude, B2 is calculated as the average of climatological U250 over the region isolated in metric B1. The averaged amplitude of the jet is $35.9 \mathrm{~m} \mathrm{~s}^{-1}$ in observations. About $62 \%$ of models overestimate the amplitude of the westerly jet (Fig. 6b), consistent with Gong et al. (2014). The jet is especially strong in IPSLCM5A-LR, MRI-CGCM3, and MRI-ESM1, and weak in TAMU-CAM4.

(B3) Zonal extension of the jet: According to Winters et al. (2019), the dominant changes in the North Pacific westerly jet with longitude are characterized by an eastward extension or westward retraction, while changes with latitude are characterized by a northward or southward shift. To measure the longitudinal bias of the simulated jet position, B3 is calculated as the U250weighted average longitude

$$
\frac{\sum_{\varphi_{1}}^{\varphi_{2}} \sum_{\theta_{1}}^{\theta_{2}} \theta \cdot U(\theta, \varphi) \cdot \cos (\varphi)}{\sum_{\varphi_{1}}^{\varphi_{2}} \sum_{\theta_{1}}^{\theta_{2}} U(\theta, \varphi) \cdot \cos (\varphi)},
$$

where $\theta$ is the longitude, $\varphi$ is the latitude, and $U$ is the climatological U250. B3 is thus defined as the sum of longitude multiplied by climatological U250 divided by the sum of $\mathrm{U} 250$ across the longitudinal span of $100^{\circ} \mathrm{E}-$ $120^{\circ} \mathrm{W}\left(100^{\circ}-240^{\circ}\right.$ in calculation) within the region selected in B1 and B2. About $72 \%$ of models have B3 larger than observation $\left(161.59^{\circ} \mathrm{E}\right)$ (Fig. $\left.6 \mathrm{c}\right)$, suggesting an eastward jet extension. The eastward jet extension is especially significant in CMCC-CESM, MRI-CGCM3, and MRI-ESM1 (Figs. 5 and 6c).

(B4) Meridional shift of the jet: Similar to B3, this metric aims to evaluate the basic state biases induced by meridional shifts of the jet. We calculate the U250weighted average latitude as 

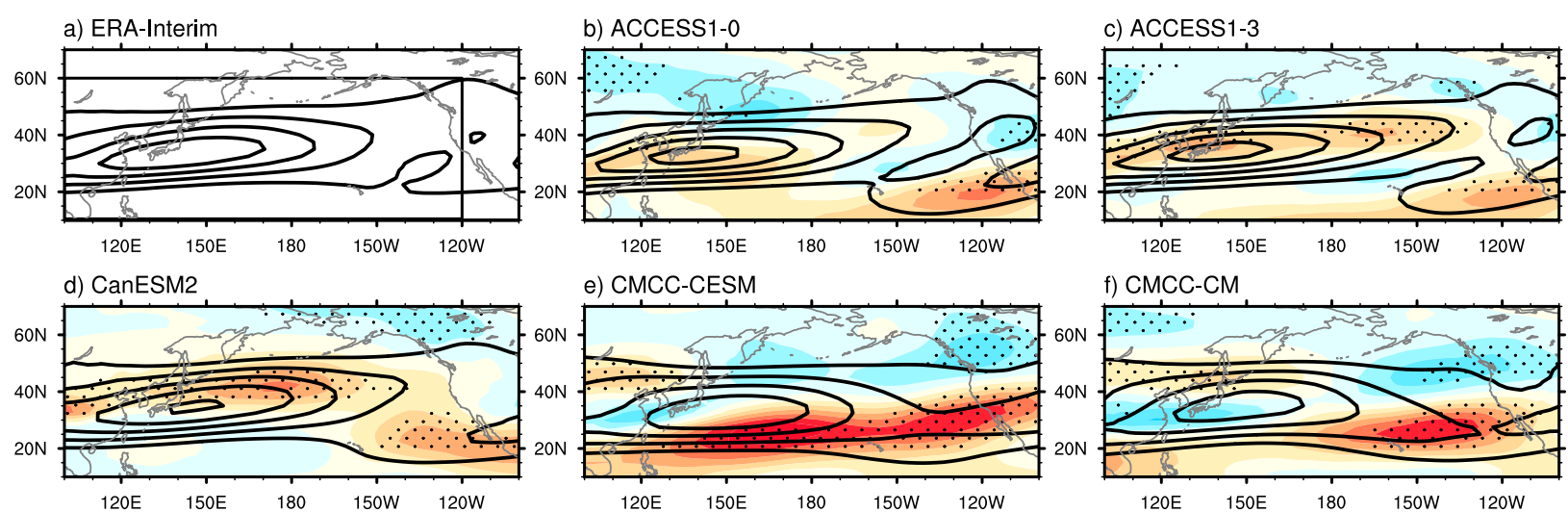

e) CMCC-CESM
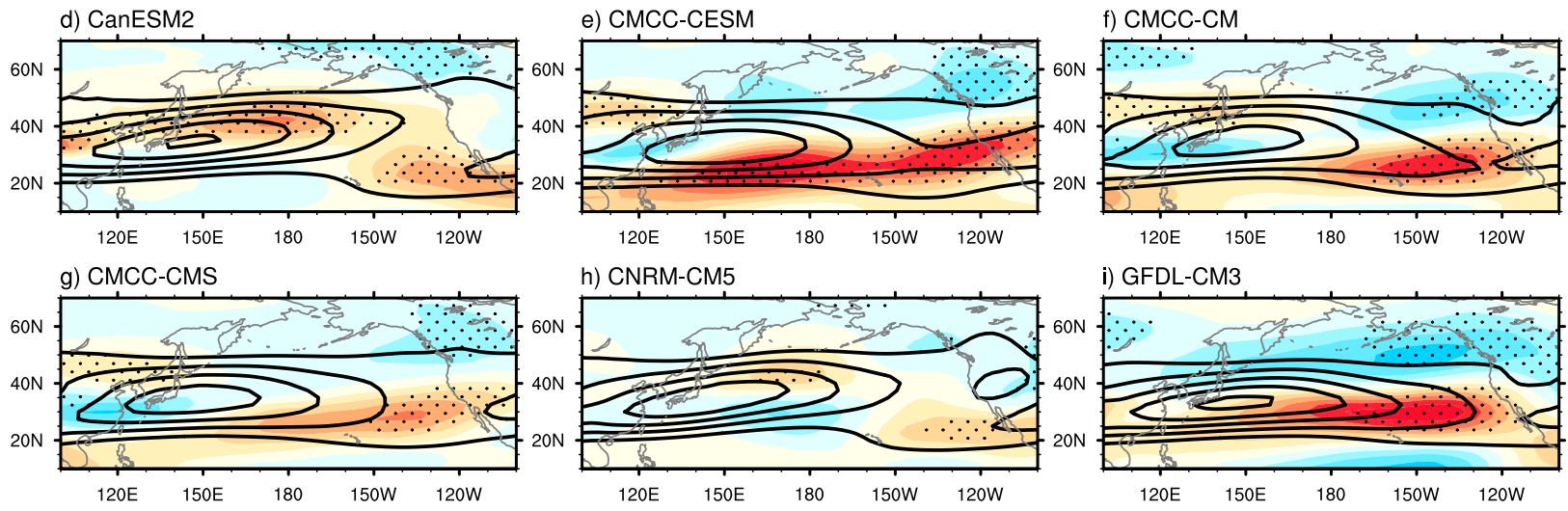

h) CNRM-CM5
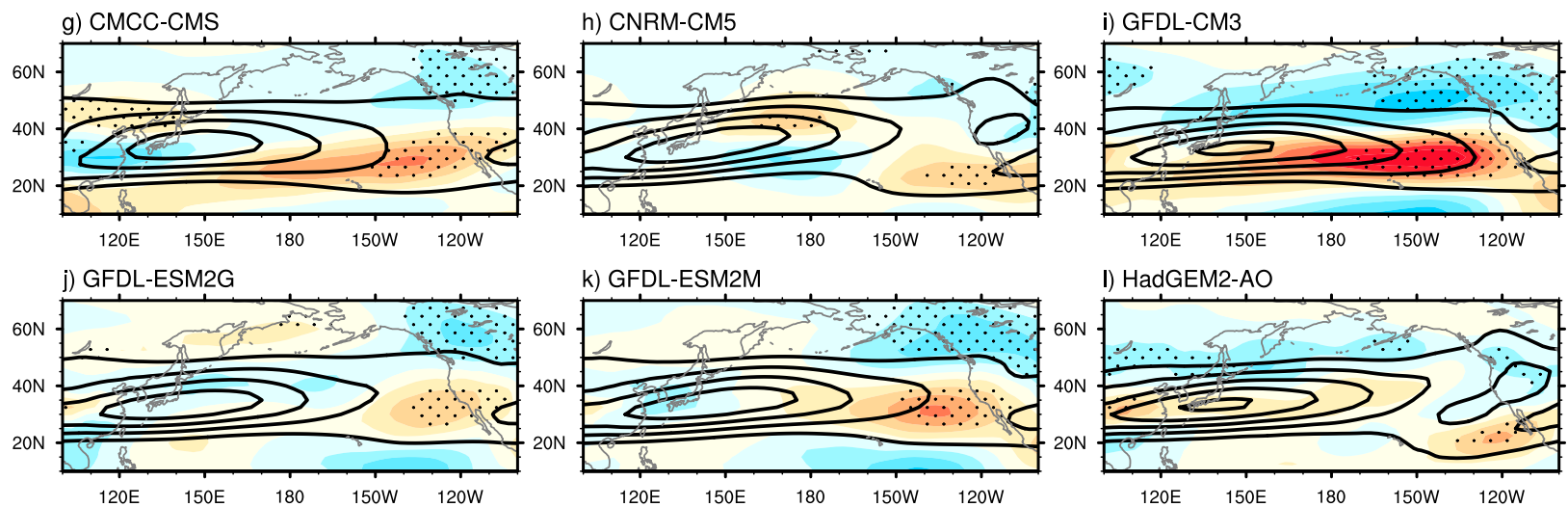

k) GFDL-ESM2M
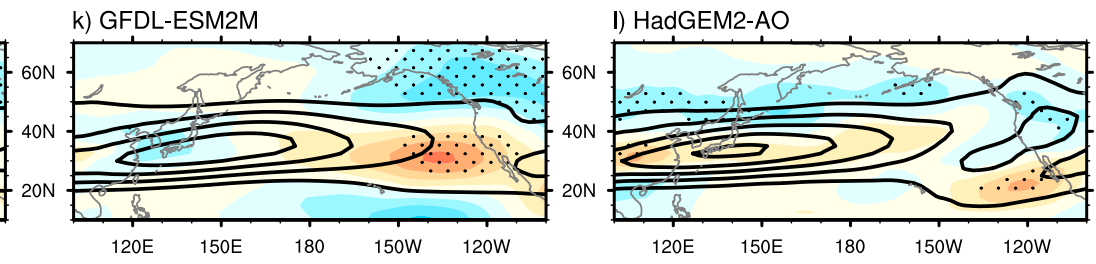

m) HadGEM2-CC

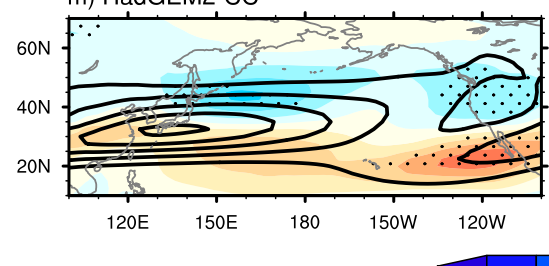

n) IPSL-CM5A-LR

o) MIROC5
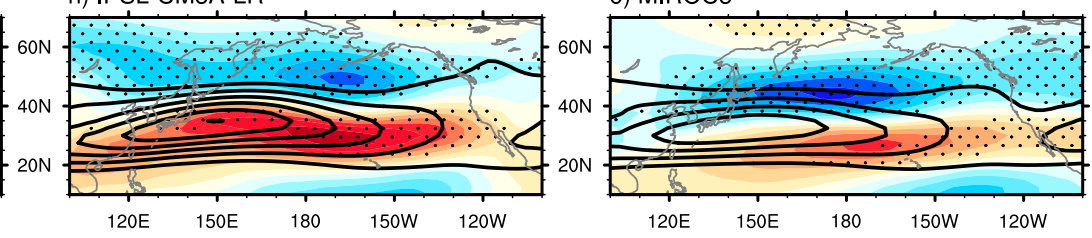

$\begin{array}{llllllllllllllll}-14 & -12 & -10 & -8 & -6 & -4 & -2 & 0 & 2 & 4 & 6 & 8 & 10 & 12 & 14\end{array} \quad\left[\mathrm{~ms}^{-1}\right]$

FIG. 5. Climatology of U250 (contour interval: $10 \mathrm{~m} \mathrm{~s}^{-1}$ starting from $20 \mathrm{~m} \mathrm{~s}^{-1}$ ) in (a) observations and (b)-(dd) models. Shading denotes the model biases, defined as the difference between the modeled and observed U250. Dotted areas indicate significant biases exceeding the $95 \%$ confidence level according to the two-tailed Student's $t$ test. Black box in (a) represents the region over $10^{\circ}-60^{\circ} \mathrm{N}$, $100^{\circ} \mathrm{E}-120^{\circ} \mathrm{W}$.

$$
\frac{\sum_{\varphi_{1}}^{\varphi_{2}} \sum_{\theta_{1}}^{\theta_{2}} \varphi \times U(\theta, \varphi) \times \cos (\varphi)}{\sum_{\varphi_{1}}^{\varphi_{2}} \sum_{\theta_{1}}^{\theta_{2}} U(\theta, \varphi) \times \cos (\varphi)},
$$

which is the sum of latitude multiplied by climatological U250 divided by the sum of U250 over $10^{\circ}-$ $60^{\circ} \mathrm{N}, 100^{\circ} \mathrm{E}-120^{\circ} \mathrm{W}$ (black box in Fig. 5a). This region with a broader latitudinal boundary than that used in $\mathrm{B} 1-\mathrm{B} 3$ is selected to better capture the meridional shifts of the jet. B4 values less than observation $\left(34.5^{\circ} \mathrm{N}\right)$ indicate a southward shift of the jet, and vice versa. About $66 \%$ of models produce the jet with a southward shift (Fig. 6d), such as IPSL-CM5A-LR and MIROC5. When calculating over 29 models, a strong relationship is found between $\mathrm{B} 2$ and $\mathrm{B} 3$ (0.71), and $\mathrm{B} 2$ and $\mathrm{B} 4(-0.7)$, indicating that a strong jet is usually associated with an eastward extension and/or southward shift.

\section{b. Relationships between the basic state and MJO teleconnections}

We explore the relationship between the basic state metrics introduced above with the MJO teleconnection metrics (Table 3). Variations in the jet affect mostly the 

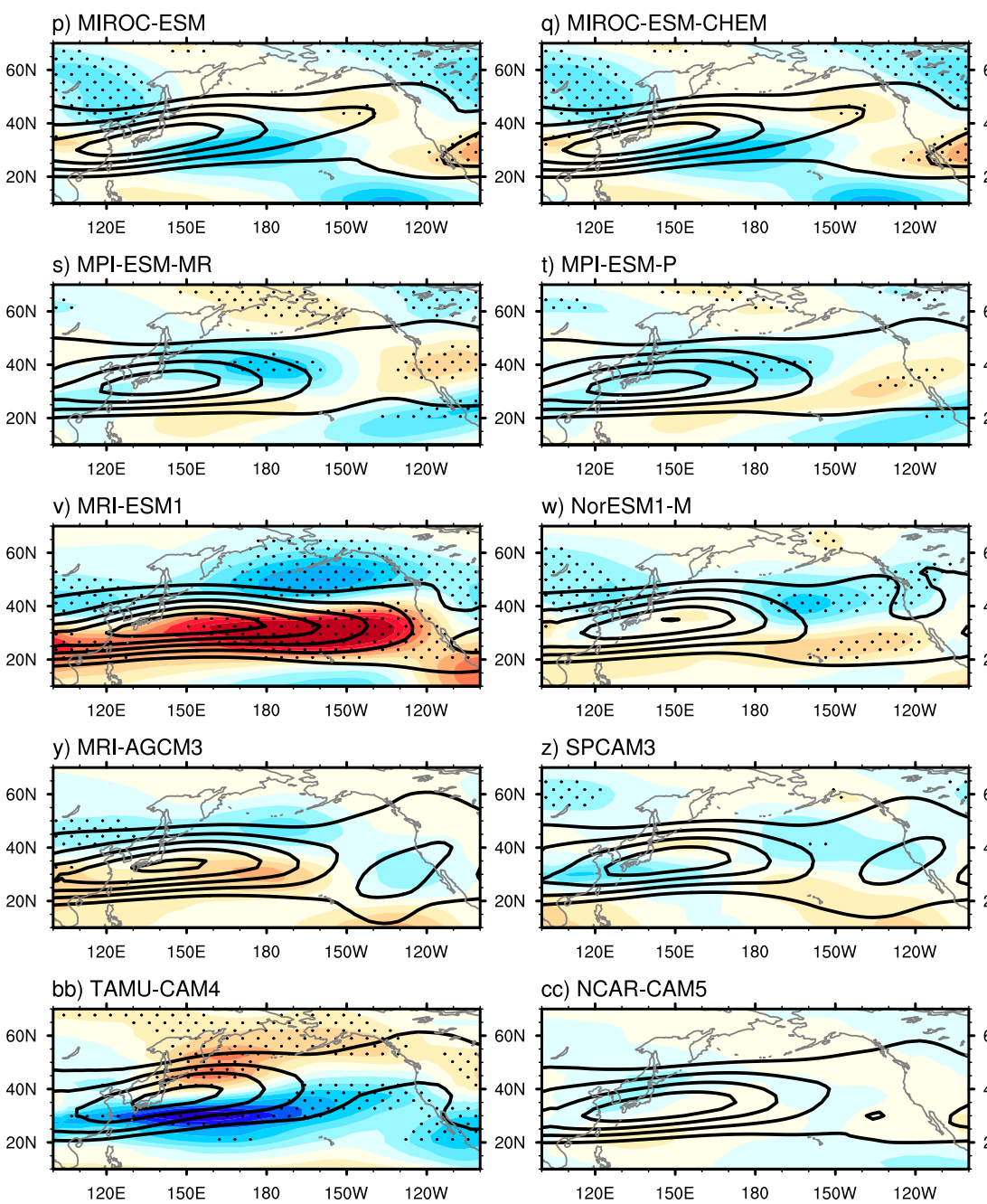

cc) NCAR-CAM5

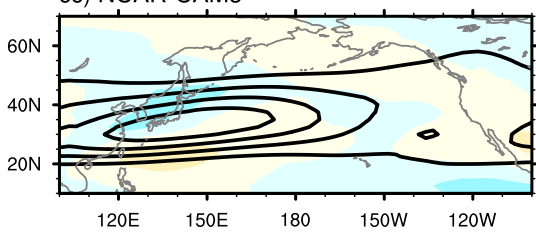

$120 \mathrm{E}$

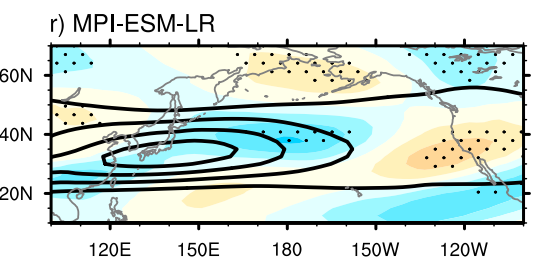

u) MRI-CGCM3

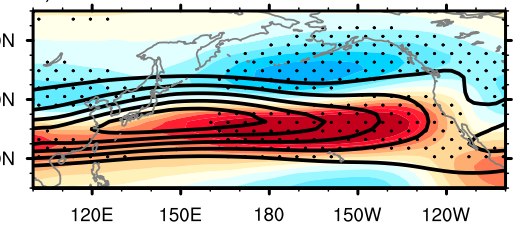

x) GISS-E2

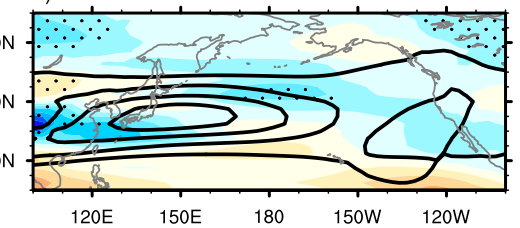

aa) SPCCSM3

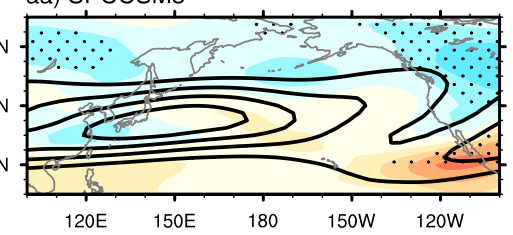

dd) ECMWF

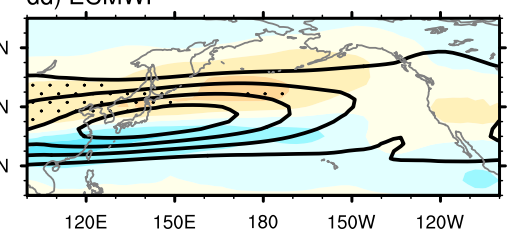

$\left[\mathrm{ms}^{-1}\right]$

FIG. 5. (Continued)

east-west position (T3) of MJO teleconnections. A stronger westerly jet (B2), an eastward extended jet (B3), and a southward shifted jet (B4) all coincide with an eastward shift in MJO teleconnections (T3). A positive relationship (correlation coefficient at 0.36 ) is found between the jet amplitude (B2) and teleconnection amplitude (T2), indicating that models that produce a stronger westerly jet may also produce stronger MJO teleconnections. The above relationships will be further examined with the LBM experiments in section 5 along with the mechanisms.

RMSE of U250 over the subtropical jet region (B1) has negligible correlation $(-0.05)$ with teleconnection pattern (T1) when all 29 models are considered. However, when the bias of the jet becomes large (RMSE $>4 ; 8$ models), the basic state significantly correlates negatively with MJO teleconnection patterns (correlation coefficient at -0.83 ) such that a larger bias leads to a larger degradation of teleconnection pattern simulation.

\section{MJO and basic state impacts on MJO teleconnections: $L B M$ experiments}

\section{a. LBM description, setup, and control run}

The LBM is constructed by linearizing the primitive equations about a basic state and the linear response to a prescribed MJO heating is derived to simulate MJO teleconnections (Mori and Watanabe 2008; Henderson et al. 2017). The model has a horizontal resolution of $\mathrm{T} 42\left(\sim 2.8^{\circ}\right.$ grid resolution) and 20 unevenly spaced sigma $(\sigma)$ levels in the vertical. The magnitude of the biharmonic diffusion coefficient defined by the $e$-folding decay time is set to $2 \mathrm{~h}$ for the largest wavenumber. The dissipation time scale for Newtonian damping and 


\section{a) B1 RMSE}

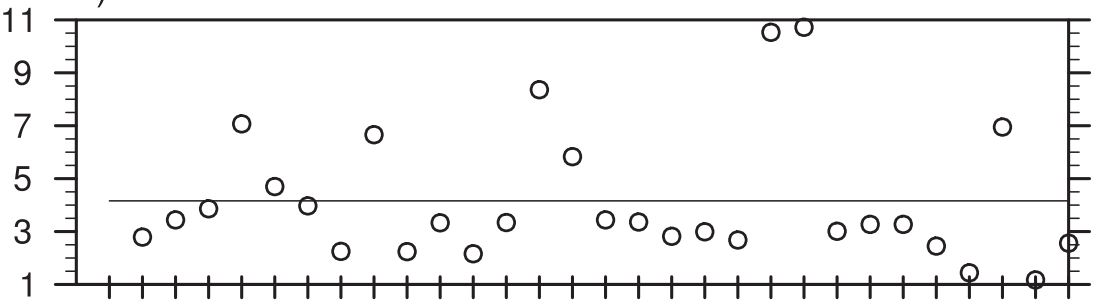

b) B2 Jet amplitude (m/s)

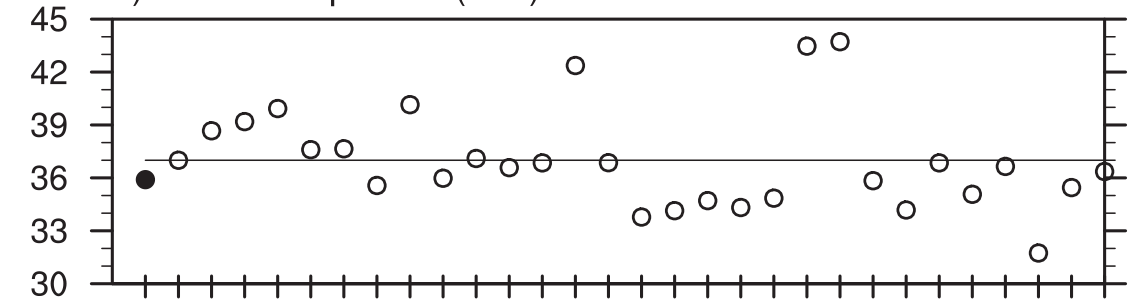

c) B3 Zonal extension of the jet $\left(^{\circ}\right)$

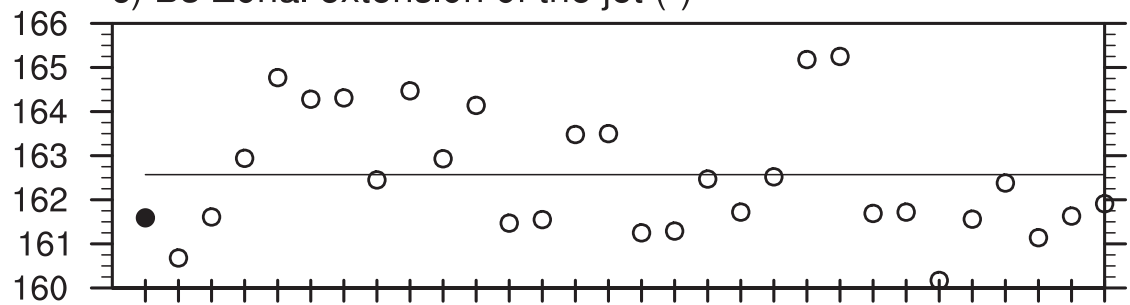

d) B4 Meridional shift of the jet $\left({ }^{\circ} \mathrm{N}\right)$

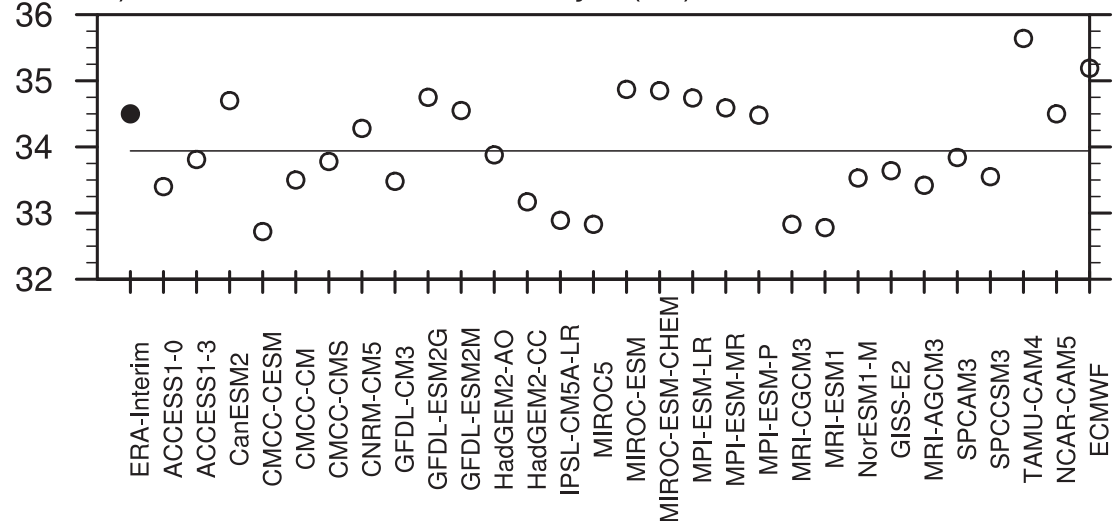

FIG. 6. (a) RMSE (B1), (b) jet amplitude (B2), (c) zonal extension of the jet (B3), and (d) meridional shift of the jet (B4) for observations (closed circles) and each model (open circles). Solid lines represent the multimodel mean.

Rayleigh friction is set to 0.5 days for the lower boundary layers $(\sigma \geq 0.9)$ and the top two levels $(\sigma \leq 0.3)$, with the remaining layers having a time scale of 20 days (Mori and Watanabe 2008; Henderson et al. 2017). These parameters are not altered for sensitivity experiments.

In the LBM, the heating and basic state can be separately modified, which allows an investigation of the relative impact of MJO and basic state on MJO teleconnections. The model basic state for the control run uses the monthly climatology during October to March generated from observations over the period of 19792017. The model is forced by the observational daily apparent heat source $Q_{1}$ (Yanai et al. 1973) computed as

$$
Q_{1}=\frac{\partial s}{\partial t}+\mathbf{v} \cdot \nabla s+\omega \frac{\partial s}{\partial p},
$$

where $\mathbf{v}$ is the horizontal velocity, $\omega$ is the vertical velocity, and $s$ is the dry static energy defined as $s=C_{p} T+g z$, 
TABLE 3. Correlations between MJO teleconnection and basic state metrics that exceed $90 \%$ confidence level based on a two-tailed test: (T1) pattern CC, (T2) relative amplitude, (T3) east-west position; (B1) RMSE, (B2) jet amplitude, (B3) zonal extension of the jet, and (B4) meridional shift of the jet. Correlation between B1 and T1 in bold text denotes the result based on 8 models with RMSE $>4$. Correlation between B2 and T2 in bold text represents the result after removing the outlier model HadGEM2-AO from calculation. For these correlations, results for all models are shown in parentheses.

\begin{tabular}{|c|c|c|c|}
\hline & $\mathrm{T} 1$ (pattern) & T2 (amplitude) & T3 (east-west position) \\
\hline B1 (RMSE) & $-\mathbf{0 . 8 3}(-0.05)$ & & 0.56 \\
\hline B2 (amplitude) & & $\mathbf{0 . 3 6}(0.13)$ & 0.58 \\
\hline B3 (zonal extension) & & & 0.55 \\
\hline B4 (meridional shift) & & & -0.53 \\
\hline
\end{tabular}

where $C_{p}$ is the specific heat capacity of air at constant pressure, $T$ is the temperature, $g$ is the gravitational acceleration, and $z$ is the height. An eastward propagating anomalous $Q_{1}$ is obtained following Henderson et al. (2017). We first removed the daily climatological seasonal cycle and constructed composites of anomalous $Q_{1}$ from MJO phase 1 to 8 based on the phase definition in Wheeler and Hendon (2004). Then the eight $Q_{1}$ phase composites are interpolated linearly with an assumption of 5 days per phase to mimic an observed boreal winter MJO cycle of about 40 days (Alaka and Maloney 2012; Henderson et al. 2016). This eastward propagating forcing (Fig. 7) is applied once in the LBM experiments; that is, the forcing is not cyclic (a cyclic MJO forcing leads to same conclusions; not shown). We only specify $Q_{1}$ anomalies in $30^{\circ} \mathrm{S}-30^{\circ} \mathrm{N}$ to focus on the forcing from the tropics.

The LBM Z500a response averaged 5-9 days after MJO phase 3 (hereafter referred to as "phase 3 teleconnection"; average over model days 16-24 considering 5-day per phase) and the observational reference are shown in Fig. 8. Although the amplitude is weaker, the control run reasonably captures the observed Z500a pattern over the PNA region (pattern correlation is 0.79 ). In the following sections, various $\mathrm{MJO}$ and basic state sensitivity runs (Table 4) are performed with this $\mathrm{LBM}$ to investigate the relative impact of $\mathrm{MJO}$ and basic state changes on MJO teleconnections.

\section{b. Impact of MJO propagation on teleconnection persistence}

In section 3, we found that when a model produces a less coherent and poor eastward MJO propagation, the teleconnections tend to persist longer. This finding is further supported with an LBM experiment. To mimic a nonpropagating MJO event (Kim et al. 2014a), the propagating anomalous $Q_{1}$ used in the control run is set to remain stationary after reaching MJO phase 4 (referred to as the Nonprop_MJO run), and thus the imposed MJO heating does not propagate across the Maritime Continent. We use the observed MJO heating rather than heating profiles from poor MJO propagation models to reduce the possible influence from other biases of MJO characteristics such as horizontal and vertical structure. Using the heating profiles obtained from a poor MJO propagation model (e.g., HadGEM2AO) led to a similar conclusion. Note that by gradually decreasing the amplitude of $Q_{1}$ with an $e$-folding time of 10 days after reaching $\mathrm{MJO}$ phase 4 does not change the conclusion (not shown). The pattern $\mathrm{CC}$ between the phase 3 teleconnection (e.g., Fig. 8a) and 5-day running average of Z500a response starting from model day 16 is calculated over the PNA region (similar to the concept of autocorrelation). The results for the control and

\section{a) MJO (Control vs Fast_MJO run)}

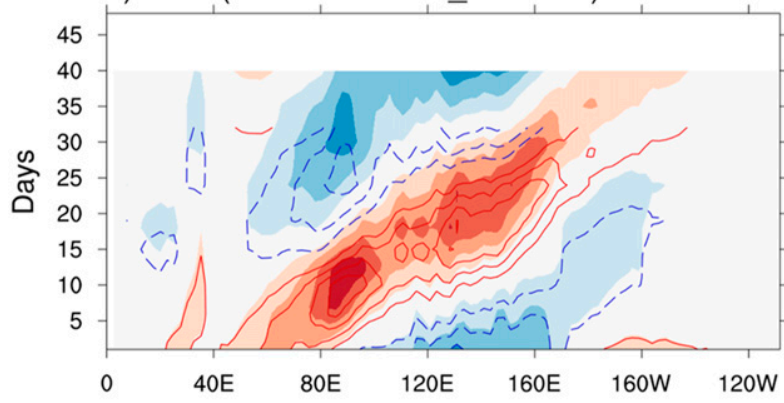

b) MJO (Control vs Slow_MJO run)

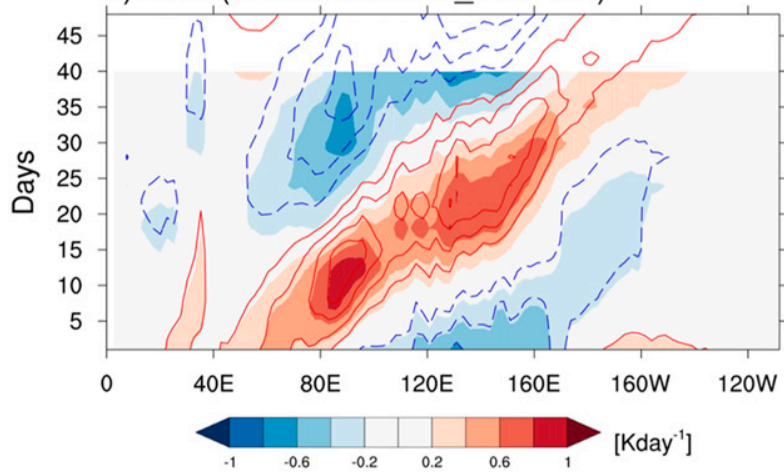

FIG. 7. The propagating MJO forcing used in LBM control run (shading; average over $10^{\circ} \mathrm{S}-10^{\circ} \mathrm{N}$ ) and in the (a) Fast_MJO and (b) Slow_MJO runs (contour; interval: $0.2 \mathrm{~K} \mathrm{day}^{-1}$ ). 


\section{a) Control run}

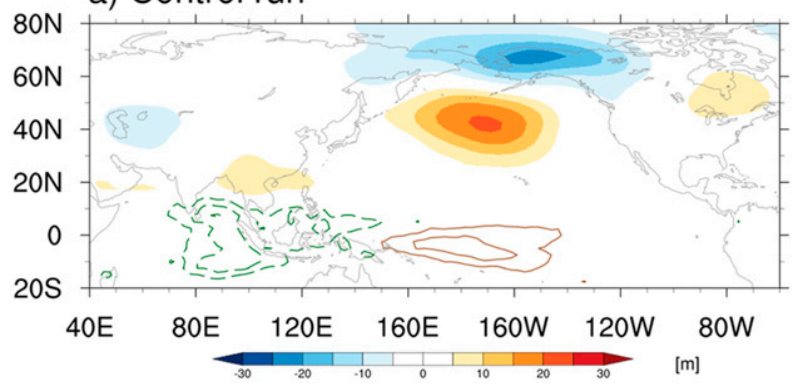

b) ERAI/NOAA Phase3

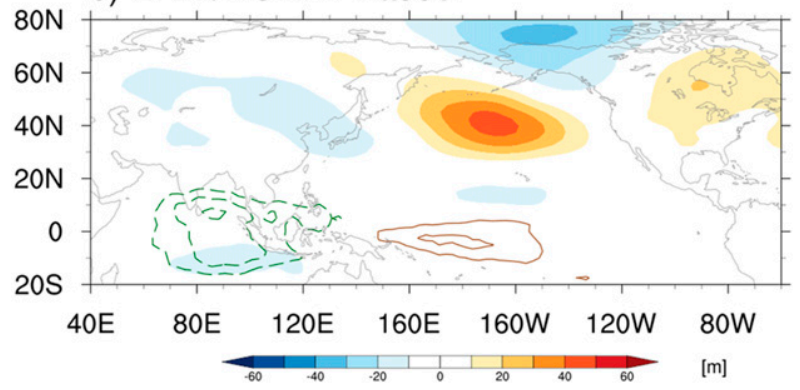

FIG. 8. (a) Phase 3 teleconnection in the LBM and the (b) observational reference (shading). Contour in (a) is the 1000- to 200-hPa averaged anomalous observational $Q_{1}$ for MJO phase 3 (average over model days 11-15): green (brown) represents MJO heating (cooling) with interval of $0.4 \mathrm{~K} \mathrm{day}^{-1}$. Contour in (b) is the composite of OLR anomaly over days in MJO phase 3: green (brown) represents enhanced (suppressed) MJO convection with interval of $10 \mathrm{~W} \mathrm{~m}^{-2}$.

Nonprop_MJO runs are shown in Fig. 9. Day 1 is the pattern CC calculated between phase 3 teleconnection and 16-20-day averaged Z500a response, day 2 is pattern CC between phase 3 teleconnection and 17-21-day averaged Z500a response, and so on. The persistence of MJO teleconnections is defined as the length of the time period (unit: days) during which the pattern $\mathrm{CC}$ remains larger than 0.5 (details in Part I). In the control run, phase 3 teleconnection persists for 10 days before transitioning to a different pattern or decay as the MJO propagates consistently with observations. In the Nonprop_MJO run, phase 3 teleconnection persists two times longer (until 20 days) than the control run. This sensitivity of teleconnection persistence to MJO propagation is consistent with Zheng and Chang (2019). During the transition of equatorial MJO events from heating anomalies of one sign to the opposite sign, the forced extratropical response will gradually change sign, which interfere destructively with the anomalies generated by the previous phases and lead to a decay of MJO teleconnections. If the $\mathrm{MJO}$ is nonpropagating, destructive teleconnection signals cannot be generated later, which gives rise to a longer persistence of teleconnections. Although opposite-sign heating anomalies may be initiated afterward over the Indian Ocean, they are usually very weak for the nonpropagating MJO events (Feng et al. 2015). The results above support the hypothesis that the longer persistence of MJO teleconnections simulated by most of the current GCMs (Part I) may be due to the exaggerated Maritime Continent barrier effect of the MJO in models (Fig. 1).

\section{c. Impact of MJO propagation speed on teleconnection amplitude}

As discussed in section 3, a fast propagating MJO may lead to weaker teleconnections than a slow propagating MJO (Bladé and Hartmann 1995; Yadav and Straus 2017; Goss and Feldstein 2018; Zheng and Chang 2019). This influence is tested through an LBM experiment by varying the speed of the propagating anomalous $Q_{1}$ from 5-day per phase (phase speed at $\sim 5 \mathrm{~m} \mathrm{~s}^{-1}$, control run) to 4-day per phase (phase speed at $\sim 6 \mathrm{~m} \mathrm{~s}^{-1}$; Fast_MJO run) and 6-day per phase (phase speed at $\sim 4 \mathrm{~m} \mathrm{~s}^{-1}$; Slow_MJO

TABLE 4. Description of LBM experiments with a 50-day integration.

\begin{tabular}{|c|c|c|c|}
\hline \multicolumn{2}{|c|}{ Experiments } & MJO & Basic state (BS) \\
\hline \multicolumn{2}{|c|}{ Control run } & $\begin{array}{l}\text { Observational (Obs) } Q_{1} \text { propagating eastward from } \\
\text { phase } 1 \text { to } 8 \text { with speed at } 5 \text {-day per phase }\end{array}$ & $\begin{array}{l}\text { Obs October-March climatology over } \\
\text { period of 1979-2017 }\end{array}$ \\
\hline \multirow[t]{3}{*}{ MJO runs } & Nonprop_MJO & Obs $Q_{1}$ set to be stationary after reaching phase 4 & As in the control run \\
\hline & Fast_MJO & Obs $Q_{1}$ propagating with speed at 4-day per phase & \\
\hline & Slow_MJO & Obs $Q_{1}$ propagating with speed at 6-day per phase & \\
\hline \multirow[t]{6}{*}{ BS runs } & StrongU_BS & As in the control run & ACCESS1.3 \\
\hline & WeakU_BS & & $\begin{array}{l}\text { Obs climatology plus opposite model } \\
\text { bias of ACCESS } 1.3\end{array}$ \\
\hline & EastU_BS & & GFDL-ESM2M \\
\hline & WestU_BS & & $\begin{array}{l}\text { Obs climatology plus opposite model } \\
\text { bias of GFDL-ESM2M }\end{array}$ \\
\hline & SouthU_BS & & MIROC5 \\
\hline & NorthU_BS & & $\begin{array}{l}\text { Obs climatology plus opposite model } \\
\text { bias of MIROC5 }\end{array}$ \\
\hline
\end{tabular}




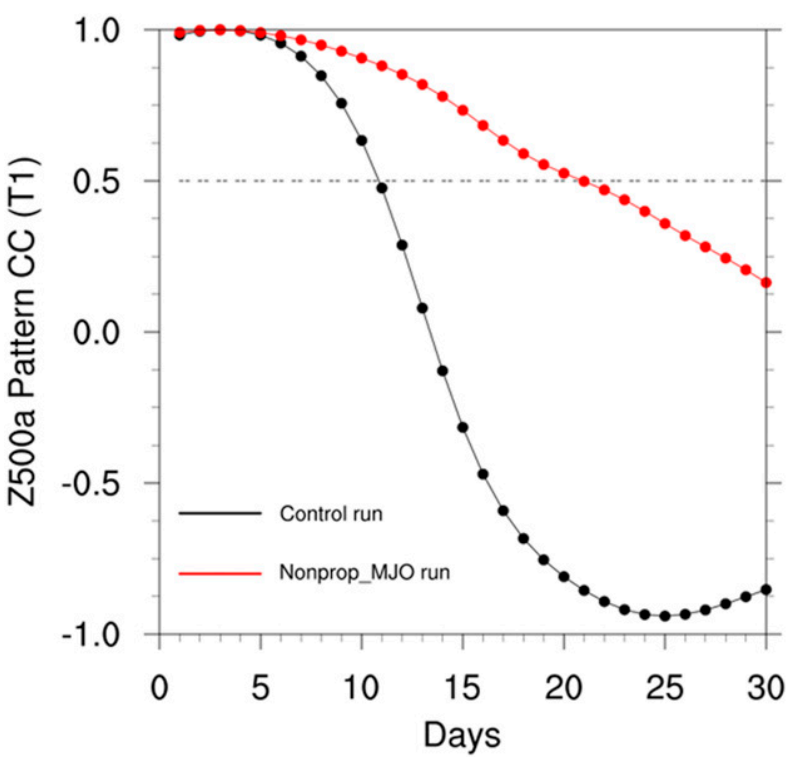

FIG. 9. Pattern CC between phase 3 teleconnection (i.e., Fig. 7a) and 5-day running average of Z500a over the PNA region in the control run (black line). Red line is similar to black line but for the Nonprop_MJO run. Persistence is defined as number of days that pattern $\mathrm{CC}$ being larger than 0.5 (dashed line).

run). The MJO propagation will thus last for 32 days for the Fast_MJO run (Fig. 7a) and 48 days for the Slow_ MJO run (Fig. 7b), which coincides approximately with the spread of model bias of the MJO period (Fig. 2c). Phase 3 teleconnection in the Fast_MJO (average over model days 14-21 considering 4-day per phase) and Slow_ MJO run (average over model days 18-27 considering 6-day per phase) are compared in Fig. 10. The extratropical response becomes stronger in the Slow_MJO than that in the Fast_MJO run [relative amplitude (T2): 1.12 vs 0.86 , consistent with the relationship found in section 3 . Because most GCMs have faster MJO propagation and stronger MJO teleconnections than the observed, the LBM results (faster MJO propagation induces weaker teleconnections) suggest that the bias of teleconnection amplitude in GCMs is not directly attributed to biases in the MJO propagation speed or the MJO impact is overpowered by the basic state impacts discussed below.

\section{d. Impact of jet characteristics on teleconnection amplitude and position}

Bias in the amplitude and position of the subtropical westerly jet may lead to bias in the amplitude and position of MJO teleconnections (section 4). However, bias in the jet amplitude is usually accompanied by bias in the jet position (section 4), thus obscuring their independent impact on MJO teleconnections. To understand the independent impact of jet amplitude,
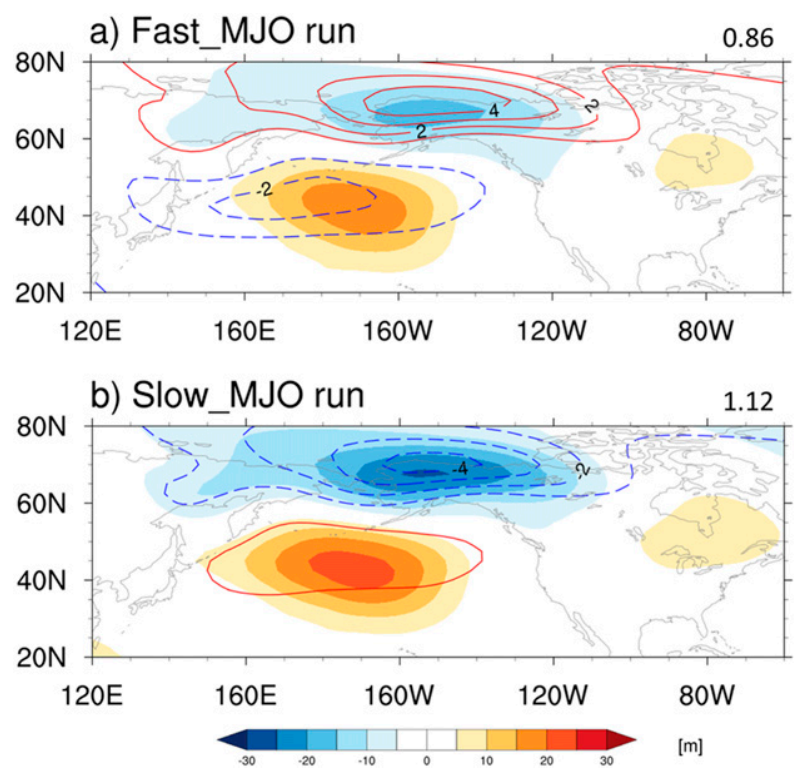

FIG. 10. Phase 3 teleconnection (shading) in the (a) Fast_MJO and (b) Slow_MJO runs. Contours are the difference from the control run (interval: $1 \mathrm{~m}$ ). Values on the top right are MJO teleconnection metric T2 (relative amplitude). T2 larger (smaller) than 1 indicates a stronger (weaker) response than the control run.

zonal extension, and meridional shift on MJO teleconnections, three sets of paired experiments are carried out. Their corresponding basic states are derived from models following the selection criteria: First, models with remarkable biases in B2 (jet amplitude), B3 (zonal extension of the jet), or B4 (meridional shift of the jet) are selected based on Fig. 6. Remarkable jet biases are defined as basic state metrics within the top $25 \%$ among models for B2 and B3, and bottom $25 \%$ for B4, given that models are generally biased to a stronger westerly jet (larger B2) with an eastward extension (larger B3) and/or a southward shift (smaller B4). Some models (e.g., IPSL-CM5A-LR and MRI-ESM1) are double- or triple-counted. Hence, to isolate the impact of a certain jet bias, models with a remarkable bias in the other two jet categories are excluded. With these criteria, the basic state from ACCESS1.3 (Fig. 5c) is prescribed in the LBM to investigate the impact of the stronger jet on MJO teleconnections (StrongU_BS run). GFDLESM2M (Fig. 5k) is used to examine the impact of the eastward jet extension (EastU_BS run) on MJO teleconnections, and MIROC5 (Fig. 5o) used for the southward jet shift (SouthU_BS run). The opposite biases from the selected models are added to the observed climatology to analyze the opposite jet impacts on MJO teleconnections (Table 4). We use the model bias to test impacts of the basic state on MJO teleconnections instead of modifying the observed basic 


\section{a) ERA-Interim}

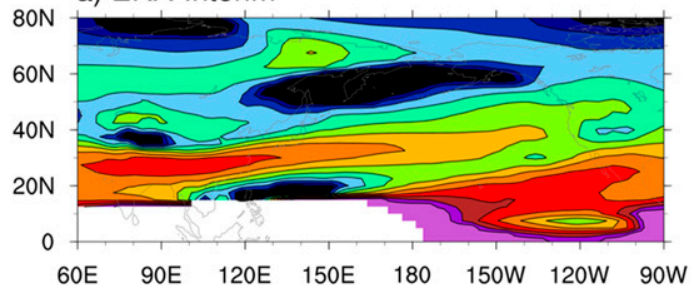

c) GFDL-ESM2M

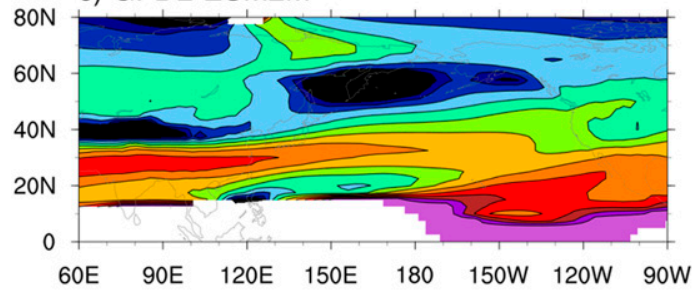

b) ACCESS1-3

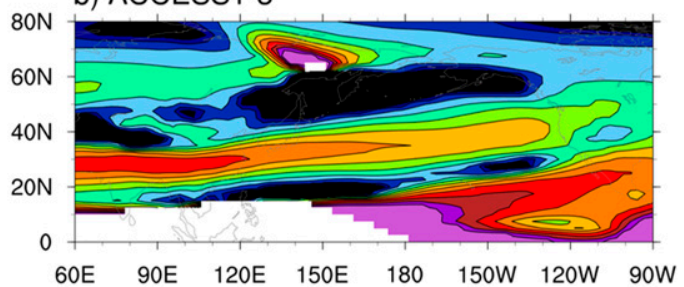

d) MIROC5

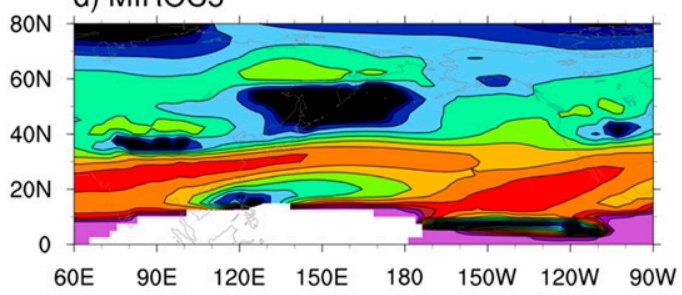

Ks

FIG. 11. Stationary wavenumber $K_{S}$ derived from climatological U250 on Mercator coordinates. Black areas are where meridional gradient of absolute vorticity $\beta_{M}$ is negative. Regions of easterly zonal winds are in white.

state directly because 1) understanding impacts of the model bias is the main focus of this study and 2) to maintain the geostrophic balance, it is hard to perturb one characteristic of the jet while keeping all other characteristics completely unchanged.

Mechanisms of the basic state impacts on MJO teleconnections are examined by examining the stationary wavenumber $K_{S}$ on Mercator coordinates, which is obtained following Hoskins and Ambrizzi (1993):

$$
K_{S}=a\left(\frac{\beta_{M}}{\bar{U}_{M}}\right)^{1 / 2},
$$

where $a$ is Earth's radius, $\bar{U}_{M}$ is the mean zonal wind divided by the cosine of latitude, and $\beta_{M}$ is equivalent to $\beta^{*}=\partial f / \partial y-\partial^{2} \bar{u} / \partial y^{2}$ defined as the meridional gradient of absolute vorticity on a sphere multiplied by the cosine of latitude:

$$
\begin{aligned}
\beta_{M} & =\cos \varphi \frac{1}{a} \frac{\partial \zeta_{a}}{\partial \varphi} \\
& =\left[2 \Omega-\left(\frac{1}{\cos \varphi} \frac{\partial}{\partial \varphi}\right)^{2}\left(\frac{\cos ^{2} \varphi \bar{U}_{M}}{a}\right)\right] \frac{\cos ^{2} \varphi}{a},
\end{aligned}
$$

where $\zeta_{a}$ is the absolute vorticity and $\Omega$ is the rotation rate of Earth. Model $K_{S}$ is compared with observations in Fig. 11. White areas are where waves are dissipated since $\bar{U}_{M}<0$. Black shadings denote regions where $\beta_{M}<0$. According to the Rossby wave theory (Hoskins and Karoly 1981; Hoskins and Ambrizzi 1993), waves reflect at the turning latitude where zonal wavenumber $k$ equals to $K_{S}$ (thus meridional wavenumber $l=0$ ) or where $\beta_{M}<0$ (thus $l^{2}<0$ ) and refract toward regions with high $K_{S}$. As shown in observations (Fig. 11a), regions with $\beta_{M}<0$ are at the poleward and equatorward sides of the subtropical westerly jet due to the strong meridional curvature $\left(\partial^{2} \bar{u} / \partial y^{2}\right)$ there, and the jet, where $K_{S}$ is large, acts as a westerly waveguide. Thus the MJOforced Rossby waves, especially those with zonal wavenumbers 3 and 4, propagate eastward along the jet and emanate at the jet exit region; Rossby waves with zonal wavenumbers 1 and 2 penetrate beyond the jet and propagate directly to the PNA region following $K_{S}$ contours 1 and 2 (Seo and Lee 2017). A bias in $\beta_{M}$ and $K_{S}$ in a model can thus lead to biases in the position and propagation of MJO teleconnections.

Results of the sensitivity experiments (Fig. 12) are explained based on the above mechanisms. In a comparison of StrongU_BS (Fig. 12a) and WeakU_BS run (Fig. 12b), when the jet becomes stronger, MJO teleconnections tend to be stronger ( $\mathrm{T} 2$ as 1.13) accordingly, and vice versa when the jet is weaker. This is consistent with ray theory (Hoskins and Karoly 1981) in that the energy (i.e., amplitude) of stationary Rossby waves is proportional to the speed of the mean zonal wind along a ray. The jet amplitude also seems to affect the east-west position of teleconnection patterns that a stronger jet leads to an eastward shift in MJO teleconnections over the North Pacific (Fig. 12a). This is because a stronger jet is associated with a stronger meridional curvature $\left(\partial^{2} \bar{u} / \partial y^{2}\right)$, thus a smaller $\beta_{M}$ on the poleward and equatorward sides of the jet (i.e., larger 
a) StrongU_BS run (ACCESS1-3)

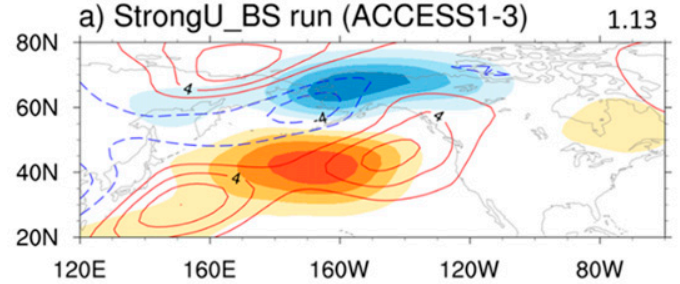

c) EastU_BS run (GFDL-ESM2M) 1.06

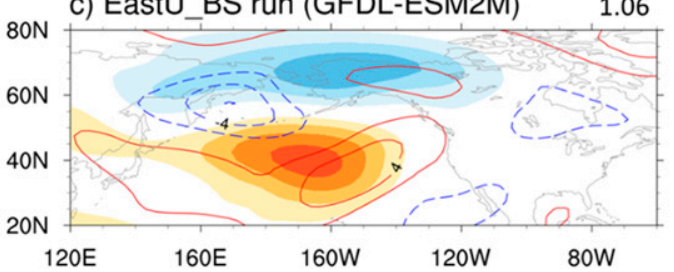

e) SouthU BS run (MIROC5)

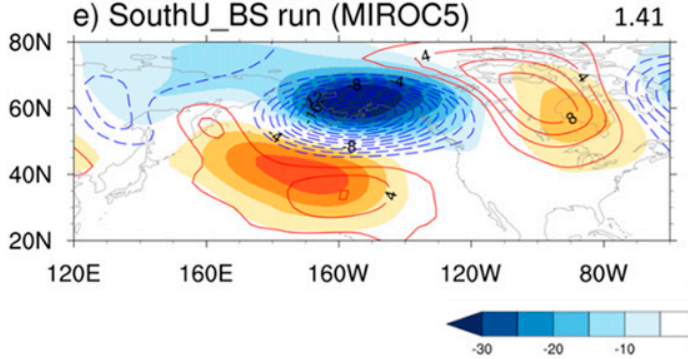

b) WeakU_BS run

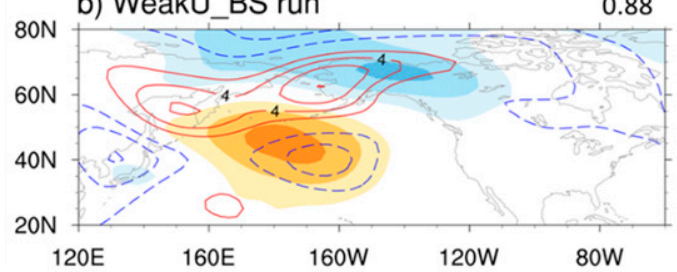

d) WestU_BS run

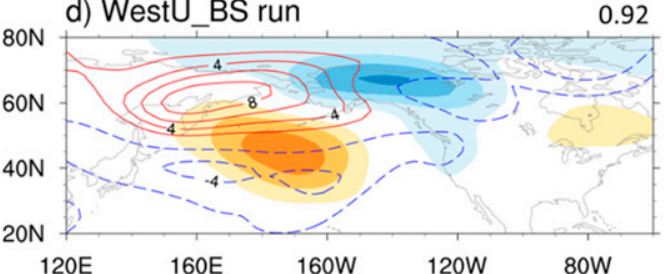

0.92

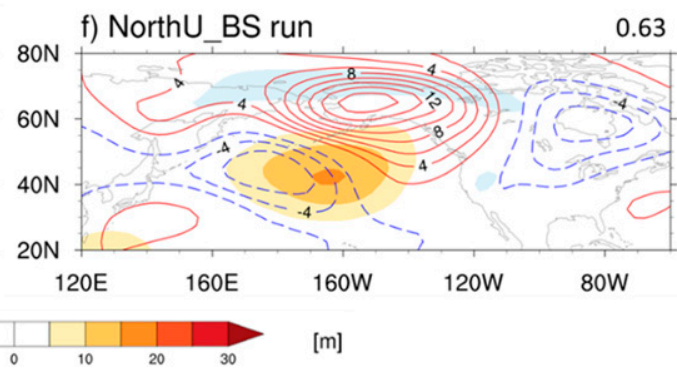

FIG. 12. As in Fig. 9, but for the (a) StrongU_BS, (b) WeakU_BS, (c) EastU_BS, (d) WestU_BS, (e) SouthU_BS, and (f) NorthU_BS runs (contour interval: $2 \mathrm{~m}$ ). Anomalous $Q_{1}$ used in these experiments is the same as in the control run, i.e., the observational eastward propagating $Q_{1}$.

areas of $\beta_{M}<0$ in ACCESS1.3; Fig. 11b) compared to observations (Fig. 11a). Therefore, Rossby wave propagation may be more confined to the westerly waveguide due to greater wave reflection (i.e., less meridional wave penetration beyond the jet into the extratropics) until Rossby waves reach the exit region. As a result, meridional propagation of Rossby waves into the extratropics could occur farther eastward in response to a stronger jet, illustrated by an eastward shift in MJO teleconnections as shown in Fig. 12a. When the subtropical jet extends eastward (EastU_BS vs WestU_BS run; Figs. 12c and 12d), MJO teleconnections over the North Pacific also tend to shift eastward (Fig. 12d) due to an eastward extension of the westerly waveguide (Fig. 11c).

On the other hand, a southward jet shift (SouthU_BS run; Fig. 12e) leads to stronger teleconnection amplitude (T2 as 1.41) than a northward jet shift (NorthU_BS run; Fig. 12f). This is possibly because of an easier excitation of Rossby waves when the strong absolute vorticity gradient in the jet is placed closer to the heat source and associated divergent winds (Frederiksen and Webster 1988) (see the RWS in Fig. 7 of Part I). Although this linear relationship is not found in GCMs (section 4), we found that among the $18 \mathrm{GCMs}$ that have stronger teleconnection amplitude, 12 of them have a southward shifted jet. The southward jet shift also causes changes in the teleconnection pathway: teleconnections propagate more zonally oriented (Fig. 12e) than those in response to the northward jet shift (Fig. 12f), which is discerned as the cyclonic anomaly over Alaska extending southward in the SouthU_BS run than that in the NorthU_BS run. This change in the teleconnection pathway as a result of the meridional jet shift is also discussed in Henderson et al. (2017), which may be due to the difference in the position of the turning latitude. According to Seo and Lee (2017), MJO-forced Rossby waves consist of zonal wavenumbers 1 and 2 that penetrate to Alaska and zonal wavenumbers 3 and 4 that propagate more zonally oriented. This is consistent with the distribution of $K_{S}$ (Fig. 11a); that is, shorter waves reach their turning latitudes $\left(K_{S}=k\right)$ at a lower latitude. Therefore, if $K_{S}$ contours are located more equatorward, it is expected that teleconnections will propagate in a manner that is more zonally oriented as they would encounter their turning latitudes at a lower latitude. In MIROC5 (Fig. 11d), $K_{S} 3$ and 4 contours north of the jet exit region $\left(\sim 30^{\circ}-60^{\circ} \mathrm{N}, 180^{\circ}-120^{\circ} \mathrm{W},\right)$ are shifted equatorward compared to observations (Fig. 11a). As a result, the 
poleward propagating Rossby waves would turn at a lower latitude in response to a southward jet shift, leading to a more zonally oriented wave propagation, illustrated by a southward extension of Z500a over Alaska. The southward jet shift also leads to a westward shift in MJO teleconnections over the North Pacific (Fig. 12e), which contradicts the relationship found in GCMs that a southward jet shift is correlated with an eastward shift in MJO teleconnections (section 4). This discrepancy is possibly caused by two reasons. First, the LBM is based on the linear dynamics. When the jet shifts equatorward, assuming the meridional curvature $\left(\partial^{2} \bar{u} / \partial y^{2}\right)$ is not changed, only $\partial f / \partial y$ increases as the jet locates at a lower latitude with larger planetary vorticity gradient. Thus $\beta_{M}$ will increase on both sides of the jet as seen in Fig. 11d (i.e., smaller areas of $\beta_{M}<0$ in MIROC5), which is more favorable for the poleward wave propagation occurring westward in the SouthU_ BS run compared to the NorthU_BS run. Second, the negative relationship found in GCMs between B4 (meridional shift of the jet) and T3 (east-west position) is effectively dominated by the impact from B2 (jet amplitude) which has a positive relationship with $\mathrm{T} 3$ and a negative relationship with B4. This is supported by the reduced partial correlation (correlation at -0.21 ) between T3 and B4 when controlling the effect of B2.

The above basic state experiments suggest that the eastward shift in MJO teleconnections simulated by current GCMs (Part I) can be attributed to the stronger and/or eastward extended westerly jet (Figs. 6b,c) simulated by most models, and the stronger teleconnection amplitude can be attributed to the stronger westerly jet and/or the southward jet shift (Fig. 6d).

\section{Summary and discussion}

In Part I of this study that examined 29 GCMs, it was shown that models generally produce MJO teleconnections with an eastward shift, larger amplitude, and longer persistence compared to the observed counterparts. To quantify the impacts of the simulated MJO and basic state on MJO teleconnections, various existing and newly developed MJO and basic state metrics are applied to the 29 GCMs in this study. Most models simulate an MJO with weaker amplitude, faster propagation speed, and less coherent eastward propagation than the observed. A majority of models produce a stronger Pacific westerly jet with an eastward extension or southward shift relative to observations. The above biases are significant at the $95 \%$ confidence level based on a two-tailed test of differences between observations and the multimodel mean (not shown). By calculating linear correlations between various metrics of MJO teleconnections, MJO characteristics, and basic state characteristics, it is found that models that produce realistic MJO patterns with a better and coherent eastward propagation generally produce more realistic teleconnection patterns and persistence. Models with a stronger MJO tend to simulate stronger MJO teleconnections with higher consistency between individual MJO events, and longer persistence of patterns. Models with a slower MJO propagation produce stronger MJO teleconnections. Compared to variations in MJO characteristics, the westerly jet mainly influences the eastwest position of MJO teleconnections. A stronger and/ or eastward-extended westerly jet can lead to an eastward shift in MJO teleconnections. In addition, a stronger jet may lead to stronger MJO teleconnections. Although the above relationships may not be valid for all models as the correlation is not perfect, they reveal the potential sources of the teleconnection biases.

MJO and basic state impacts on MJO teleconnections are further investigated through various LBM sensitivity experiments (Table 4) by changing the MJO propagation characteristics and by isolating impacts from variations in jet amplitude and position. Results indicate that 1) teleconnections generated in response to a nonpropagating MJO persist longer than for a propagating $\mathrm{MJO}$; 2) a faster propagating MJO produces weaker teleconnections than a more slowly propagating MJO; 3 ) a stronger and/or eastward-extended jet leads to an eastward shift in MJO teleconnections; 4) MJO teleconnections are stronger when the jet is stronger and/or shifts southward; and 5) MJO teleconnections propagate with a more zonally oriented pathway when the jet shifts southward.

Results in this study suggest that the longer persistence of MJO teleconnections found in the $29 \mathrm{GCMs}$ may be due to exaggerated Maritime Continent barrier effect of the MJO in models. The eastward shift and larger amplitude of MJO teleconnections may be attributed to biases in the jet. Therefore, to better represent MJO teleconnections, both the MJO and basic state need to be accurately simulated.

This study provides a better understanding of the relative impact of $\mathrm{MJO}$ and basic state characteristics on MJO teleconnections and the possible causes of biases in teleconnection simulations. However, characteristics of the MJO differ from event to event and the subtropical jet is also impacted by the MJO (Kang and Tziperman 2018). Interpretation is further complicated by the fact that changes in MJO teleconnections can be a result of various MJO or basic state influences. For example, a stronger MJO or less coherent MJO propagation can both lead to longer teleconnection persistence, and biases in jet amplitude and position can both lead to an east-west shift in teleconnections. The 
relative contribution from such impacts of different MJO or basic state characteristics on the same teleconnection bias merits further investigation.

The MJO and subtropical jet may be modulated by slowly varying basic state variability, such as that caused by El Niño-Southern Oscillation (ENSO; Hendon et al. 1999; Takahashi and Shirooka 2014; Henderson and Maloney 2018) or the quasi-biennial oscillation (QBO; Yoo and Son 2016; Wang et al. 2018b). The results found in this study may therefore be influenced by the model ability to simulate the observed features of interannual variability. In addition, the processes responsible for MJO teleconnections include both linear and nonlinear effects (Bladé and Hartmann 1995; Lin and Brunet 2018). The LBM used in this study has limitations in that it is based on linear dynamics, and therefore may lead to oversimplified results. After the first week, the extratropical response to the $\mathrm{MJO}$ becomes more nonlinear such that the response is asymmetric between the MJO mirror phases (Lin and Brunet 2018), which may not be presented by the LBM. The possible influence from nonlinearity will be examined in future work.

Acknowledgments. Constructive and valuable comments from three reviewers are greatly appreciated. We thank WGNE MJO Task Force members for stimulating discussions during the course of this study. We thank Dr. Xianan Jiang for providing the GASS/YoTC model data, Dr. Aneesh Subramanian for providing the ECMWF model data, Dr. Masahiro Watanabe for providing the LBM package, and Dr. Masato Mori for providing the code modifications for the LBM propagating heat source. JW was supported by NSF Grant AGS-1652289, HK was supported by NSF Grant AGS-1652289, NOAA MAPP Grant NA16OAR4310070, and KMA R\&D Program Grant KMI2018-03110. DK was supported by the U.S. DOE RGMA Program Grant DE-SC0016223, NOAA CVP Grant NA18OAR4310300, and NASA MAP Grant 80NSSC17K0227. EDM was supported by NSF Grant AGS-1841754, NOAA MAPP Grants NA16OAR4310064 and NA18OAR4310268, and NOAA CVP Grant NA18OAR4310299.

\section{REFERENCES}

Adames, Á. F., and J. M. Wallace, 2014: Three-dimensional structure and evolution of the MJO and its relation to the mean flow. J. Atmos. Sci., 71, 2007-2026, https://doi.org/10.1175/JAS-D-13-0254.1.

Ahn, M.-S., D. Kim, K. R. Sperber, I.-S. Kang, E. Maloney, D. Waliser, and H. Hendon, 2017: MJO simulation in CMIP5 climate models: MJO skill metrics and process-oriented diagnosis. Climate Dyn., 49, 4023-4045, https://doi.org/10.1007/s00382-017-3558-4.

Alaka, G. J., Jr., and E. D. Maloney, 2012: The influence of the MJO on upstream precursors to African easterly waves. J. Climate, 25, 3219-3236, https://doi.org/10.1175/JCLI-D-11-00232.1.
Bao, M., and D. L. Hartmann, 2014: The response to MJO-like forcing in a nonlinear shallow-water model. Geophys. Res. Lett., 41, 1322-1328, https://doi.org/10.1002/2013GL057683.

Bladé, I., and D. L. Hartmann, 1995: The linear and nonlinear extratropical response of the atmosphere to tropical intraseasonal heating. J. Atmos. Sci., 52, 4448-4471, https://doi.org/ 10.1175/1520-0469(1995)052<4448:TLANER>2.0.CO;2.

Cassou, C., 2008: Intraseasonal interaction between the MaddenJulian oscillation and the North Atlantic Oscillation. Nature, 455, 523-527, https://doi.org/10.1038/nature07286.

Davini, P., and Coauthors, 2017: Climate SPHINX: Evaluating the impact of resolution and stochastic physics parameterisations in the EC-Earth global climate model. Geosci. Model Dev., 10, 1383-1402, https://doi.org/10.5194/gmd-10-1383-2017.

Dee, D. P., and Coauthors, 2011: The ERA-Interim reanalysis: Configuration and performance of the data assimilation system. Quart. J. Roy. Meteor. Soc., 137, 553-597, https://doi.org/ 10.1002/qj.828.

Deng, Y., and T. Jiang, 2011: Intraseasonal modulation of the North Pacific storm track by tropical convection in boreal winter. J. Climate, 24,1122-1137, https://doi.org/10.1175/2010JCLI3676.1.

Duchon, C. E., 1979: Lanczos filtering in one and two dimensions. J. Appl. Meteor., 18, 1016-1022, https://doi.org/10.1175/15200450(1979)018<1016:LFIOAT>2.0.CO;2.

Duffy, P., B. Govindasamy, J. P. Iorio, J. Milovich, K. R. Sperber, K. E. Taylor, M. F. Wehner, and S. L. Thompson, 2003: High-resolution simulations of global climate, part 1: Present climate. Climate Dyn., 21, 371-390, https://doi.org/10.1007/ s00382-003-0339-z.

Feng, J., T. Li, and W. Zhu, 2015: Propagating and nonpropagating MJO events over Maritime Continent. J. Climate, 28, 84308449, https://doi.org/10.1175/JCLI-D-15-0085.1.

Frederiksen, J. S., and P. J. Webster, 1988: Alternative theories of atmospheric teleconnections and low-frequency fluctuations. Rev. Geophys., 26, 459-494, https://doi.org/10.1029/ RG026i003p00459.

Gong, H., L. Wang, W. Chen, R. Wu, K. Wei, and X. Cui, 2014: The climatology and interannual variability of the East Asian winter monsoon in CMIP5 models. J. Climate, 27, 1659-1678, https://doi.org/10.1175/JCLI-D-13-00039.1.

Goss, M., and S. B. Feldstein, 2018: Testing the sensitivity of the extratropical response to the location, amplitude, and propagation speed of tropical convection. J. Atmos. Sci., 75, 639655, https://doi.org/10.1175/JAS-D-17-0132.1.

Henderson, S. A., and E. D. Maloney, 2018: The impact of the Madden-Julian oscillation on high-latitude winter blocking during El Niño-Southern Oscillation events. J. Climate, 31, 5293-5318, https://doi.org/10.1175/JCLI-D-17-0721.1.

,-- , and E. A. Barnes, 2016: The influence of the MaddenJulian oscillation on Northern Hemisphere winter blocking. J. Climate, 29, 4597-4616, https://doi.org/10.1175/JCLI-D-150502.1.

— - _ and S.-W. Son, 2017: Madden-Julian oscillation Pacific teleconnections: The impact of the basic state and MJO representation in general circulation models. J. Climate, 30, 4567-4587, https://doi.org/10.1175/JCLI-D-16-0789.1.

- D. J. Vimont, and M. Newman, 2020: The critical role of nonnormality in partitioning tropical and extratropical contributions to PNA growth. J. Climate, submitted.

Hendon, H. H., C. Zhang, and J. D. Glick, 1999: Interannual variation of the Madden-Julian oscillation during austral summer. J. Climate, 12, 2538-2550, https://doi.org/10.1175/ 1520-0442(1999)012<2538:IVOTMJ >2.0.CO;2. 
Horel, J. D., and J. M. Wallace, 1981: Planetary-scale atmospheric phenomena associated with the Southern Oscillation. Mon. Wea. Rev., 109, 813-829, https://doi.org/10.1175/1520-0493(1981) 109<0813:PSAPAW $>2.0 . \mathrm{CO} ; 2$.

Hoskins, B. J., and D. J. Karoly, 1981: The steady linear response of a spherical atmosphere to thermal and orographic forcing. J. Atmos. Sci., 38, 1179-1196, https://doi.org/10.1175/15200469(1981)038<1179:TSLROA > 2.0.CO;2.

—_, and T. Ambrizzi, 1993: Rossby wave propagation on a realistic longitudinally varying flow. J. Atmos. Sci., 50, 1661-1671, https://doi.org/10.1175/1520-0469(1993)050<1661: RWPOAR $>2.0 . \mathrm{CO} ; 2$.

Jiang, X., and Coauthors, 2015: Vertical structure and physical processes of the Madden-Julian oscillation: Exploring key model physics in climate simulations. J. Geophys. Res. Atmos., 120, 4718-4748, https://doi.org/10.1002/2014JD022375.

Kang, W., and E. Tziperman, 2018: The MJO-SSW teleconnection: Interaction between MJO-forced waves and the midlatitude jet. Geophys. Res. Lett., 45, 4400-4409, https://doi.org/10.1029/ 2018 GL077937.

Karoly, D., 1983: Rossby wave propagation in a barotropic atmosphere. Dyn. Atmos. Oceans, 7, 111-125, https://doi.org/ 10.1016/0377-0265(83)90013-1.

Kim, D., and Coauthors, 2009: Application of MJO simulation diagnostics to climate models. J. Climate, 22, 6413-6436, https://doi.org/10.1175/2009JCLI3063.1.

_ J.-S. Kug, and A. H. Sobel, 2014a: Propagating versus nonpropagating Madden-Julian oscillation events. J. Climate, 27, 111-125, https://doi.org/10.1175/JCLI-D-13-00084.1.

- and Coauthors, 2014b: Process-oriented MJO simulation diagnostic: Moisture sensitivity of simulated convection. J. Climate, 27, 5379-5395, https://doi.org/10.1175/JCLI-D-1300497.1.

Lappen, C.-L., and C. Schumacher, 2012: Heating in the tropical atmosphere: What level of detail is critical for accurate MJO simulations in GCMs? Climate Dyn., 39, 2547-2568, https:// doi.org/10.1007/s00382-012-1327-y.

Liebmann, B., and C. A. Smith, 1996: Description of a complete (interpolated) outgoing longwave radiation dataset. Bull. Amer. Meteor. Soc., 77, 1275-1277.

Lin, H., and G. Brunet, 2018: Extratropical response to the MJO: Nonlinearity and sensitivity to the initial state. J. Atmos. Sci., 75, 219-234, https://doi.org/10.1175/JAS-D-17-0189.1.

,$- \ldots$, and J. Derome, 2009: An observed connection between the North Atlantic Oscillation and the Madden-Julian oscillation. J. Climate, 22, 364-380, https://doi.org/10.1175/2008JCLI2515.1.

Madden, R. A., and P. Julian, 1971: Detection of a 40-50 day oscillation in the zonal wind in the tropical Pacific. J. Atmos. Sci., 28, 702-708, https://doi.org/10.1175/1520-0469(1971)028<0702: DOADOI $>2.0 . \mathrm{CO} ; 2$

— , and — 1972: Description of a global-scale circulation cells in the tropics with a 40-50 day period. J. Atmos. Sci., 29, 1109-1123, https://doi.org/10.1175/1520-0469(1972)029<1109: DOGSCC $>2.0 . \mathrm{CO} ; 2$.

Mori, M., and M. Watanabe, 2008: The growth and triggering mechanisms of the PNA: A MJO-PNA coherence. J. Meteor. Soc. Japan, 86, 213-236, https://doi.org/10.2151/jmsj.86.213.

Mundhenk, B. D., E. A. Barnes, and E. D. Maloney, 2016: Allseason climatology and variability of atmospheric river frequencies over the North Pacific. J. Climate, 29, 4885-4903, https://doi.org/10.1175/JCLI-D-15-0655.1.

Rui, H., and B. Wang, 1990: Development characteristics and dynamic structure of tropical intraseasonal convection anoma- lies. J. Atmos. Sci., 47, 357-379, https://doi.org/10.1175/15200469(1990)047<0357:DCADSO > 2.0.CO;2.

Sardeshmukh, P. D., and B. J. Hoskins, 1988: The generation of global rotational flow by steady idealized tropical divergence. J. Atmos. Sci., 45, 1228-1251, https://doi.org/10.1175/15200469(1988)045<1228:TGOGRF>2.0.CO;2.

Seo, K.-H., and H.-J. Lee, 2017: Mechanisms for a PNA-like teleconnection pattern in response to the MJO. J. Atmos. Sci., 74, 1767-1781, https://doi.org/10.1175/JAS-D-16-0343.1.

Simmons, A., J. Wallace, and G. Branstator, 1983: Barotropic wave propagation and instability, and atmospheric teleconnection patterns. J. Atmos. Sci., 40, 1363-1392, https://doi.org/10.1175/ 1520-0469(1983)040<1363:BWPAIA $>2.0$. CO;2.

Sperber, K. R., and D. Kim, 2012: Simplified metrics for the identification of the Madden-Julian oscillation in models. Atmos. Sci. Lett., 13, 187-193, https://doi.org/10.1002/asl.378.

Stan, C., and D. M. Straus, 2019: The impact of cloud representation on the sub-seasonal forecast of atmospheric teleconnections and preferred circulation regimes in the Northern Hemisphere. Atmos.-Ocean, 57, 233-248, https:/doi.org/10.1080/ 07055900.2019.1590178.

, — , J. S. Frederiksen, H. Lin, E. D. Maloney, and C. Schumacher, 2017: Review of tropical-extratropical teleconnections on intraseasonal time scales. Rev. Geophys., 55, 902-937, https://doi.org/10.1002/2016RG000538.

Takahashi, C., and R. Shirooka, 2014: Storm track activity over the North Pacific associated with the Madden-Julian Oscillation under ENSO conditions during boreal winter J. Geophys. Res. Atmos., 119, $10663-10683$, https://doi.org/ 10.1002/2014JD021973.

Taylor, K. E., 2001: Summarizing multiple aspects of model performance in a single diagram. J. Geophys. Res., 106, 71837192, https://doi.org/10.1029/2000JD900719.

$\longrightarrow$, R. J. Stouffer, and G. A. Meehl, 2012: An overview of CMIP5 and the experiment design. Bull. Amer. Meteor. Soc., 93, 485498, https://doi.org/10.1175/BAMS-D-11-00094.1.

Tseng, K.-C., E. Maloney, and E. Barnes, 2019: The consistency of MJO teleconnection patterns: An explanation using linear Rossby wave theory. J. Climate, 32, 531-548, https://doi.org/ 10.1175/JCLI-D-18-0211.1.

Waliser, D., and Coauthors, 2009: MJO simulation diagnostics. J. Climate, 22, 3006-3030, https://doi.org/10.1175/2008JCLI2731.1.

Wang, J., H. M. Kim, E. K. Chang, and S. W. Son, 2018a: Modulation of the MJO and North Pacific storm track relationship by the QBO. J. Geophys. Res. Atmos., 123, 39763992, https://doi.org/10.1029/2017JD027977.

,-- , and $-2018 \mathrm{~b}$ : Interannual modulation of Northern Hemisphere winter storm tracks by the QBO. Geophys. Res. Lett., 45, 2786-2794, https://doi.org/10.1002/2017GL076929.

,,- D. Kim, S. A. Henderson, C. Stan, and E. D. Maloney, 2019: MJO teleconnections over the PNA region in climate models. Part I: Performance- and process-based skill metrics. J. Climate, 33, 1051-1067, https://doi.org/10.1175/JCLI-D-19-0253.1.

Watanabe, M., and M. Kimoto, 2000: Atmosphere-ocean thermal coupling in the North Atlantic: A positive feedback. Quart. J. Roy. Meteor. Soc., 126, 3343-3369, https://doi.org/10.1002/ qj.49712657017.

Wheeler, M. C., and H. H. Hendon, 2004: An all-season real-time multivariate MJO index: Development of an index for monitoring and prediction. Mon. Wea. Rev., 132, 1917-1932, https://doi.org/ 10.1175/1520-0493(2004)132<1917:AARMMI>2.0.CO;2.

Winters, A. C., D. Keyser, and L. F. Bosart, 2019: The development of the North Pacific jet phase diagram as an objective tool to 
monitor the state and forecast skill of the upper-tropospheric flow pattern. Wea. Forecasting, 34, 199-219, https://oi.org/ 10.1175/WAF-D-18-0106.1.

Yadav, P., and D. M. Straus, 2017: Circulation response to fast and slow MJO episodes. Mon. Wea. Rev., 145, 1577-1596, https:// doi.org/10.1175/MWR-D-16-0352.1.

Yanai, M., S. Esbensen, and J.-H. Chu, 1973: Determination of bulk properties of tropical cloud clusters from large-scale heat and moisture budgets. J. Atmos. Sci., 30, 611-627, https:/doi.org/ 10.1175/1520-0469(1973)030<0611:DOBPOT>2.0.CO;2.

Yoo, C., and S. W. Son, 2016: Modulation of the boreal wintertime Madden-Julian oscillation by the stratospheric quasi-biennial oscillation. Geophys. Res. Lett., 43, 1392-1398, https://doi.org/ 10.1002/2016GL067762.

— , S. Park, D. Kim, J.-H. Yoon, and H.-M. Kim, 2015: Boreal winter MJO teleconnection in the Community Atmosphere Model version 5 with the unified convection parameterization. J. Climate, 28, 8135-8150, https://doi.org/10.1175/JCLI-D-150022.1.
Zhang, C., M. Dong, S. Gualdi, H. H. Hendon, E. D. Maloney, A. Marshall, K. R. Sperber, and W. Wang, 2006: Simulations of the Madden-Julian oscillation in four pairs of coupled and uncoupled global models. Climate Dyn., 27, 573-592, https:// doi.org/10.1007/s00382-006-0148-2.

Zheng, C., and E. K. M. Chang, 2019: The role of MJO propagation, lifetime, and intensity on modulating the temporal evolution of the MJO extratropical response. J. Geophys. Res. Atmos., 124, 5352-5378, https://doi.org/10.1029/2019JD030258.

, - _ - H.-M. Kim, M. Zhang, and W. Wang, 2018: Impacts of the Madden-Julian oscillation on storm-track activity, surface air temperature, and precipitation over North America. J. Climate, 31, 6113-6134, https://doi.org/10.1175/JCLI-D-170534.1.

Zhou, S., M. L'Heureux, S. Weaver, and A. Kumar, 2012: A composite study of the MJO influence on the surface air temperature and precipitation over the continental United States. Climate Dyn., 38, 1459-1471, https://doi.org/10.1007/ s00382-011-1001-9. 